\title{
Autism, Visual Thinking, and Independence
}

\author{
Broughton Elliott
}

\author{
A thesis \\ submitted to the Victoria University of Wellington \\ in fulfilment of the requirements for the degree of \\ Master of Design Innovation
}

Victoria University of Wellington 


\section{Contents}

1. Abstract

p. 4

2. Introduction

p. 4

3. Background

p. 4

4. Research Aims

p. 6

5. Literature Review

p. 7

6. Precedent Analysis

p. 8

6.0.1. Applications

p. 8

7. Rmindr Design Processes / Experiments

p. 10

7.0.1. Research Methods

p. 10

7.0.2. Initial Sketches

p. 11

7.0.3. Design 1

p. 13

7.0.4. Design 2

p. 14

7.0.5. Design 3

p. 16

7.0.6. Design 4

p. 17

7.0.7. The Participants for the project

p. 19

7.0.8. Overview of Participants

p. 19

7.0.9. User Tests

p. 19

7.0.10. Second User Tests

p. 21

7.0.11. Final Design

p. 23

8. Conclusions

p. 25

9. Discussion

p. 25

10. Acknowledgments

p. 26

11. Bibliography

p. 27

12. Figures

p. 29

13. Appendix

p. 30

14. Ethics Approval Form

p. 33 


\begin{abstract}
This project was to design a product that could assist a group of people who live with Autism Spectrum Disorder (ASD). The product was a personal organizer application designed to help people with ASD to manage themselves without the need for help from caregiver. This project reveals the difficulties faced by people with ASD, why they need a product such as personal organizer when they grow up, and why the current market of products aimed at people with ASD is flawed. This project contains research from past studies of ASD, new knowledge from participants, their caregivers, and experiments conducted to build an application for the iPad. An application built to make daily life a bit easier for young adults living with the disorder.
\end{abstract}

\title{
Introduction
}

Picture a typical day in the life of a busy individual. They may have to get dressed, eat breakfast, go to work, do the laundry, do the grocery shopping and cook a meal for the family. How does one person remember everything they need to do in a day?

Perhaps a calendar is used with notes on each day so they are aware of major events that they need to be prepared for. The person may also use a digital scheduler, such as those found in modern smartphones or tablet computers. This allows them to mark out what they need to do down to the hour or even half hour with short text reminders. These are effective at keeping most people on track if they perhaps get distracted by other things, such as their families, friends, or Facebook accounts. A lot of people fill a day with many activities planned out with complex time schedules. However, not everybody has the same level of memory or ability to multi-task. This project focuses on a group of people who may need extra assistance in reaching or feeling that they as individuals could have the same level of self-organization and independence as others. That group of people live with autism spectrum disorder (ASD).

Autism is a "developmental disorder that impairs interaction and communication but also features repetitive behaviours and restricted interests" (Hill, 2003, p. 281). Yet because this disorder is a spectrum it can vary between individuals: from very mild cases which sometimes fall under Asperger's syndrome (AS), up to severe cases which often need a lot of assistance, otherwise known as low-functioning autism. The US Centers for Disease Control and Prevention (CDC) in 2013 released figures for the prevalence of autism in the United States, they revealed that 1 in 50 children lived with the disorder (around $2 \%$ of the population)(Willingham, 2013). In New Zealand it is estimated 1 in every 100 people live with ASD (Johnston, 2012). This means that close to 40,000 people in New Zealand live with the disorder. Most people with autism struggle to be independent because of symptoms or behaviours associated with the disorder. For example, a person with ASD attempts to do the grocery shopping but has forgotten the small steps to get that task done.

\section{Background}

Growing up I wondered why it seemed harder for me to fully understand project briefs without some form of visual representation. I later discovered that this trait is shared with those living with ASD, but it can be a bigger problem for them. The autistic brain takes longer to develop therefore autistic individuals' development is often slower. A study by the University of California (UCLA) revealed that the "connections between brain regions that are important for language and social skills grow much more slowly" in people with ASD, rather and those who don't live with ASD (Mena, 2011). While teaching autistic children in special needs classes is useful, what happens when they grow up and out of them? How independent are they? Can they do their own washing; or can they cook a meal? While there has been a focus on young children with autism, there is not much, if any, support for young adults with the disorder when they leave school, and move into the grown up world. Scott Michael Robertson, vice president of the Autistic Self-Advocacy Network (ASAN), states that "most media attention focuses exclusively on young autistic children while commonly ignoring autistic adolescents and 
adults" (Robertson, 2008). While young adults with ASD can get assistance from their parents, supervisors, or teachers, these supports are not always available, especially during a busy working week. The aim of this research was to explore a method of teaching someone with ASD to organize and do daily tasks, assigned to them by their caregiver, even if that person is not around to guide them.

Firstly, an exploration was conducted to discover what products are already available and aimed specifically at persons who live with ASD. One of the main things that have been evident from studies is that people with ASD usually respond well to instructions if visual aids are present. Visual aids are objects like photographs with text connected to them for reference. An example of this is an account from American doctor of animal science, Professor Dr. Temple Grandin. She lives with autism and describes in chapter one of her book 'Thinking in Pictures' that

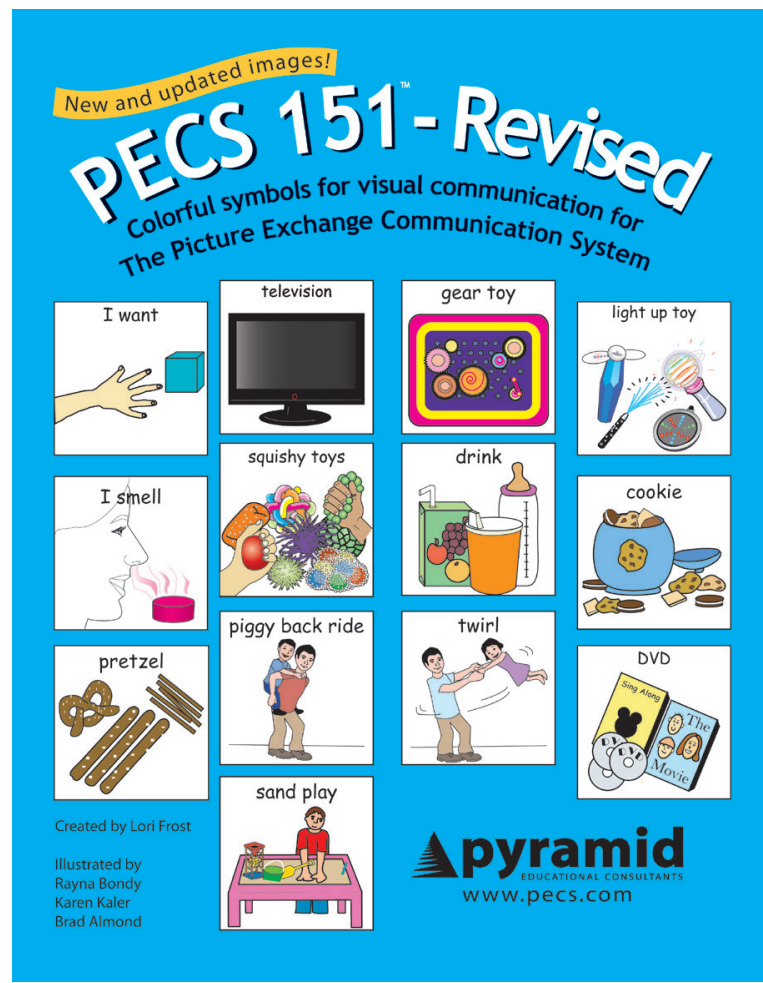

Figure 1: examples of PEC's for visual communication
One of the most profound mysteries of autism has been the remarkable ability of most autistic people to excel at visual spatial skills while performing so poorly at verbal skills. When I was a child and a teenager, I thought everybody thought in pictures. I had no idea that my thought processes were different (Grandin, 2006, p.17).

Visual aids are an effective tool for learning for most individuals, but for people with living with ASD they are invaluable. Researchers at the University of Montreal determined that people living with ASD "concentrate more brain resources in the areas associated with visual detection and identification" while less in "the areas used to plan and control thoughts and actions" (Samson, 2011). Visuals are used in many forms to present various forms of information to people so they can understand it better. Pie charts as an example are sometimes used to display data in business meetings so clients can picture the results of their ventures or potential areas of interest. A report by William C. Bradford of Indiana University, USA states that while $5 \%$ of the American population are experiential learners (for example: doing, touching, clinical work, or role-playing exercises), $65 \%$ are visual learners and need to be able to see what they are going to be doing to comprehend it (Bradford, 2011, p. 1). Visuals are needed for a lot of people to grasp information, just not as much as people with ASD.

Various visual aids are available for people with ASD. Susan Dodd mentions in her book that some of the most effective visual supports for ASD people are photographic sequences, individualized calendars, timetables or menus because people with ASD "tend to perceive and focus upon details rather than the whole picture" (Dodd, 2004, p. 167). However, what is also obvious, especially in special needs classes, is that visual aids (also known as, Picture Exchange Communication Systems (PECS) come as a set of simple printed drawings of individual objects. An example may be a cartoon drawing of a girl washing their hands with a small text subtitle underneath stating the task. This may aid a group of people learning how to do a task for themselves. However, these forms of visual aids do not explain in enough detail what is required of the person to do that task. 
For example, there are a number of steps when breaking down the process of hand washing. First, there is a matter of finding the soap in the bathroom. Secondly, the person has to scrub it around in the hands to create lather. Thirdly, they have to wash it off under the running water in the sink and finally, then dry the hands with a towel. Not only are these steps important, but there needs to be reminders such as, to ensure the water is not set too hot or cold, or a cue for when a new bar of soap needs to be unpackaged for use, or a prompt for how long to scrub or rinse for. So a process that appears simple initially actually has a lot of small details, which can be confusing for someone who has trouble processing a sequence of instructions.

While visuals are a useful way to explain a task, it is also important that they only feature the required information, and nothing unnecessary. A way to understand why removing unnecessary elements from visuals is important, is information overload. The Cambridge dictionary describes information overload as being "a situation in which you receive too much information at one time and cannot think about it in a clear way" (Cambridge, 2014). An example of this is when a person is trying to navigate to a destination in their car. They may have to turn off the car radio because they cannot concentrate on where they have to go because the sound from the radio is distracting them from driving and navigating at the same time. When someone living with ASD is viewing an image, unnecessary elements in that image can have a similar effect.

\section{Research Aims}

This project's research question is how can digital media alleviate the cognitive symptoms associated with ASD? The sub-questions are: What are the cognitive symptoms? And what sort of digital media is likely to be effective in alleviating these symptoms?

There are two main symptoms of ASD. These can have an impact on the person's ability to perform at tasks. The first is known as selective attention. Selective attention is when the person is able to process some information but the rest sometimes gets forgotten. This normally happens when too much information is fed to the person at once verbally (Burack, 1994). The second cognitive symptom is rote memory. This occurs when for instance the person may remember all the quotes from a film, but not remember small things such as their phone number, home address, or things accompanying with particular feelings or emotions (Dodd, 2004). Both of these symptoms are common reasons for why someone with ASD might have difficulty being independent. While the symptoms may not be curable, they could be alleviated or worked around with the right sort of product.

The digital media product selected for this project was a new form of a task scheduler for the iPad. This scheduler goes further in-depth than the current reminder/scheduling applications already available for tablets and computers. The typical calendar works fine for most people, but those who sometimes have trouble processing information, or remembering what to do, may need something more detailed.

To begin the project, the first thing that needed to be established was the type of product that would be useful to young adults with ASD. It was apparent that a good product to make as a personal organizer would be an application for a tablet or smartphone. This was because applications are already being used by people with ASD to help process information and social cues (May, 2013). An application for a tablet computer was decided upon also because it sits between both a computer and a smartphone size-wise, while also allowing the use of touch and swiping inputs for navigation of the application. Joan Brasher of Vanderbilt University, Nashville, USA says that

Augmentative and alternative communication devices which employ symbols, gestures, pictures and speech output have been used for decades by people who have difficulty speaking. Now, with the availability of apps that emulate those devices, the iPad offers a more accessible, cheaper and more user-friendly way to help minimally verbal children with autism to communicate (Brasher, 2013). 
The iPad could potentially be a great learning tool for those now in their adult years as well. Tablet computers are also quite portable so they would be handy for some users with ASD who move from place to place quite frequently. However, it was important that the application should be able to work on multiple devices, such as the person's desktop computer if they had to use that instead of a tablet. For this thesis the Apple iPad was selected as the device to focus on. The iPad is being utilised by many autism researchers/teachers, as well as the people with the disorder themselves (Brandon, 2011). In July of 2011 it was reported that 9.3 million iPads had been sold (61.3 percent of tablets sold) while the other major tablet companies such as Samsung and Acer which use Google's operating system Android only managed to sell just under half the number of iPads combined (Tofel, 2011).Nonetheless, the application built as part of this project could also be available to other operating systems such as Android or Windows to extend to a broader audience.

The organizer application was developed as a website to make the product available on multiple devices and not just an iPad. It also provided the opportunity to test how it would work and look on both a computer, and a tablet, so it could be fine-tuned for each. Also, a website meant that it could be downloaded to a participant's device quickly and easily for testing.

Anybody (not just those with ASD) who struggles to understand how to complete simple tasks, such as brushing their teeth, can benefit from a personal organizer application. Schedules are useful for managing tasks and reminding us of what we need to do in our daily lives. Those who have difficulty understanding or processing information need to have something they can refer to and use himself or herself without the assistance of a caregiver or teacher. This application is designed to help people with ASD feel more independent; which is essential if individuals are to feel autonomous and have a sense of accomplishment.

\section{Literature Review}

To develop a better understanding of ASD and its symptoms, a selection of journal articles and books were studied to see what has already been discovered in the field of ASD. This research would also help determine design decisions such as the applications screen layouts and the type of elements it should and shouldn't feature.

In Selective Attention and Perceptual Load in Autism Spectrum Disorder an experiment was carried out to test whether the perceptual load (amount of task-relevant information) of a person with ASD was low causing distractions to interfere. The test results showed that people with ASD did seem to get distracted more easily as predicted. The author states that the findings in this test "explain the superior visual search abilities that have consistently been found among individuals with ASD" (Anna Remington, 2009, p. 1392).

Another study was undertaken in Japan known as the Children's responses to the image of self, peer experiment. The experiment proved that children with ASD responded or engaged longer if visuals included their face or similar, unlike when the image was of somebody the person did not know. This experiment demonstrated that people who do not live with ASD often dislike seeing photos of them as it makes them feel self-conscious. People with ASD on the other hand feel the opposite and like seeing themselves in the imagery because it is something they are very familiar with and know applies to them (Wakako Sanefuji, 2011).

In Thinking in Pictures by Dr. Temple Grandin who lives with ASD, she discusses her difficulty in life to understand concepts such as how the church system worked, and that through a separation of the visual elements of the concept; it helped her to understand how the system worked much more clearly. Grandin says "I think in pictures. Words are like a second language to me... when somebody speaks to me, his words are instantly translated into pictures... One of the most profound mysteries of autism has been the remarkable ability of most autistic people to excel at visual spatial skills while performing so poorly at verbal skills" (Grandin, Temple, 1996, p. 3). 
She also states that "I store information in my head as if it were on a CD-ROM disc. When I recall something I have learned, I replay the video in my imagination" (Grandin, Temple, 1996, p. 8).

There is further evidence of Grandin's way of thinking in Understanding Autism by Susan Dodd, she states that a majority of people with ASD are 'visual learners' that "respond more effectively to visual stimuli than to auditory stimuli". Dodd further discusses the benefits of visual learning stating that it can help them to "make sense of the world" as well as of other people (Dodd, 2004, p. 165). Dodd also mentions in her book that people with ASD "tend to perceive and focus upon details rather than the whole picture" (Dodd, 2004, p. 167).

More evidence in a document by the National Autistic Society of the United Kingdom says, "Many people with ASD are thought to be visual learners, so presenting information in a visual way can help to encourage and support people's communication, language development and ability to process information. It can also promote independence, build confidence and raise self-esteem" (Visual Support from National Autistic Society, p. 3).

This research was a big influence in selecting to build an application with a focus on visuals. The people discussed in this section have all stated the importance of visuals rather than text because it has been scientifically proven time and time again by them, that they are the most effective guidance techniques for ASD. This research has also been an influence in selecting to make user (or in this case caregiver) generated content a major feature. As the Children's responses to the image of self, peer experiment revealed, making the content familiar to the user more effectively keeps them engaged with the application. Therefore reassures them that the content is for them, and nobody else. All of this literature played a part in the development of the application.

\section{Precedent Analysis}

Visual Aids Communication Pack - Released in 2009 by ASD Visual Aids (physical product)

\section{Retail Price: \$400NZ}

One product on the market aimed towards children with autism or children who have communication difficulties is called 'visual aids'. Visual aids is a pack of placement

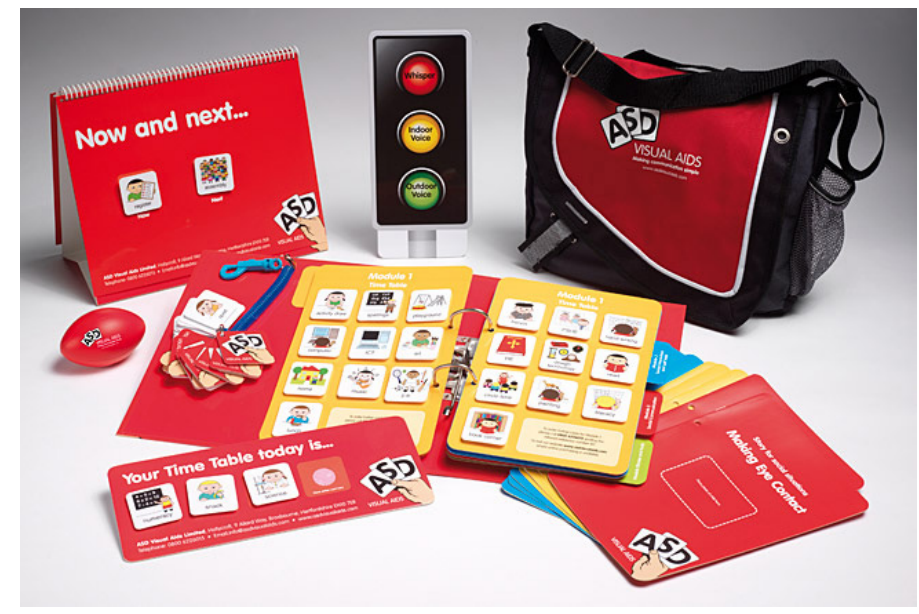

Figure 2: Visual Aids Communication Pack boards and cards containing simple time table, social interaction, and communication symbols designed for laying out visual schedules, and representing user instructions (ASD (Autism Spectrum Disorder) Communication Pack, 2009). There are a few issues with this product. The symbols used to represent some of the tasks can quite easily be misunderstood or misinterpreted. Secondly, the symbols are simple to the point where a child with ASD will not engage much as they do not look real or like the user doing the task. Also, the pack does not come with the option to create your own visual cards. The product also retails for $\$ 400 \mathrm{NZ}$ which is expensive. Finally, the visual symbols are not broken down into the steps required to complete the tasks either which is sometimes very important when working with a child with ASD. Because they are physical cards they can get lost as well which taking into account the price of the product could be a real problem.

\section{Applications}

Through an early precedent analysis of applications that are designed to meet the needs of children/adults with the ASD, most are catered towards visual communication of simple 
objects people use in their daily lives. However, the applications detailed in the following section are commonly very basic and appear to be designed for people who understand still images as symbols, but that symbol may still not be enough as it is a freeze frame of a situation and is not showing the steps taken in a sequence such as a video. The person who has ASD and is viewing these simple images may not feel they relate to the image as it is not a picture/photo of them, or someone they know doing the task presented. Also, some applications were aimed towards caregivers and parents of children with ASD rather than something the child could use themselves.

The following are apps for the iPad that are more advanced and relate to this research project:

\section{Choiceworks - Released in 2012 by Bee Visual, LLC}

\section{iTunes App Store Price: \$19NZ}

This application is designed as a visual checklist for children with ASD who need guidance throughout the day as to what tasks they need to get done, and how long they should take to complete each task. When a task is completed the user drags the visual
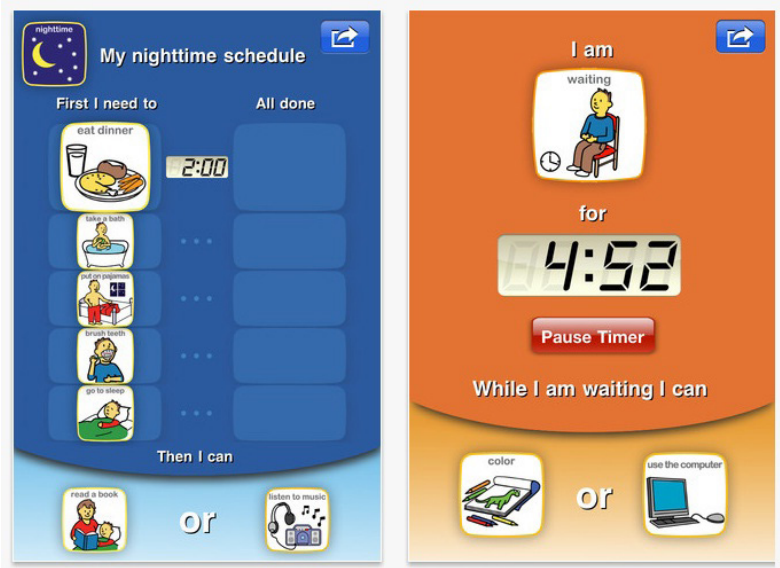

Figure 3: Choiceworks symbol from one side of the screen to the other which checks it off. The user is given a set countdown timer for each task which the person has to complete that activity within. The caregiver is given the ability to use the pre-added visual symbols or add their own in as well as audio to match them. There are problems with this application though. For instance, the application does not have a video upload function if the person with ASD responds better to watching something that demonstrates what they need to do. The application also does not go into detail for each task which may leave the user confused as to what they are required to do which along with the countdown timer ticking away, could lead to the person getting anxious and stressed. Also, all the tasks are visible on the schedule at once which depending on the number could feel quite daunting for a young person with ASD. The schedule is divided into day and night which also may be a problem as the user may not realise the day has changed to night, or remembered to switch from one schedule to the other.

\section{Augie AAC - Released in 2011 by Intervention Development}

\section{iTunes App Store Price: \$210NZ}

Augie AAC is a communication application for children with ASD who struggle to speak through verbal communication but can communicate through images. The user can set up sentences such as "I want..." using preloaded visual symbols installed on the application. Augie AAC also includes a standard calendar which can have simple

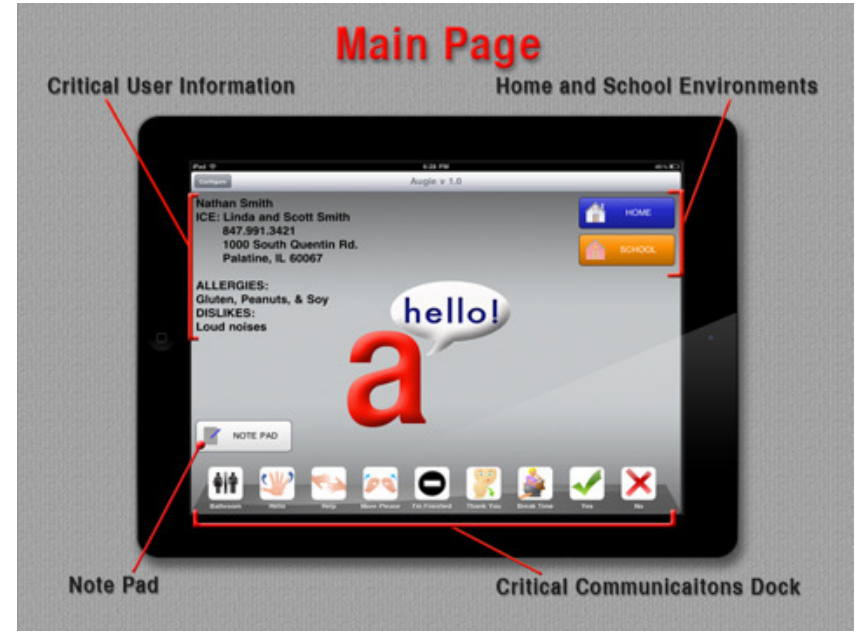

Figure 4: Augie AAC static symbols placed on it to represent things happening in the next few days, weeks, or months ahead. There are quite a few negatives of this application however. First, the calendar only includes preloaded visuals that are hard to distinguish as to what they actually represent. Second, the application tries to display too many things at once on one screen. Finally, the visuals cannot be altered, do not animate, and overall the whole visual experience is very 


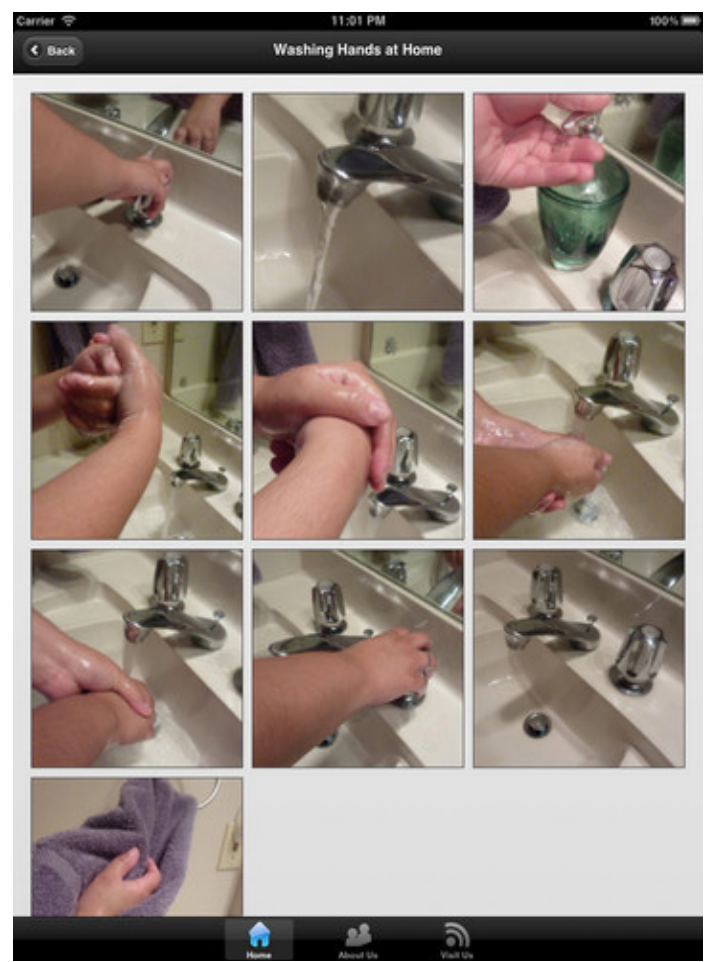

Figure 5: Autism Activity Routines dated in appearance, and not interesting enough for a lot of ASD people to use it for very long if at all. The application also feels like it is aimed more towards caregivers, and teachers, rather than the person with ASD who will be using it most of the time.

\section{Autism Activity Routines - Released in April 2012 by Zone in for Autism}

\section{iTunes App Store Price: Free}

This application is basically designed as a learning tool for children with ASD who need to learn simple day to day tasks such as how to wash their hands. The application displays each activity as very basic image sequences displaying each step. This application may work for some children with ASD, but the images are not always clear as to what needs to be done at each step. Also, the sequence may get read in the wrong order as it is not fully clear whether it is meant to read left to right, or top to bottom.

It has become clear that most of the applications (and physical products) already on the market aimed towards people with ASD are designed as 'one size fits all' products. This is a flawed way of designing for ASD because the disorder is a spectrum which can vary as to what elements or features help the people more or less. Linda Brandenburg of the Kennedy Krieger institute states that "If you've met one child with autism, well, you've met one child with autism," (Brandenburg, 2009). What she means is that ASD individuals are all unique, and have different requirements. A feature of an application may be very useful to one person, but the next person may require that element to be presented differently to be of use to them. This thesis attempts to move beyond these somewhat ineffective attempts at catering to ASD and create something new that could help more people with the disorder, rather than just a select few.

\section{Rmindr Design Processes / Experiments}

To build the application, web language based programming was used. This involved utilizing a combination of HTML, CSS, and JavaScript code simultaneously. Web scripts were selected to build the application because they allow the composition to be tested on different devices (tablets, computers, and smartphones) without having to change scripting languages to specifically cater to each. Using web scripts also gave the freedom of conversion to a packaged format for online stores such as iTunes, if the application were to be marketed as a commercial product later.

\section{Research Methods}

A qualitative research approach was selected for the project. Qualitative research involves a few steps. The first involves studying literature already available on the research topic (if any). Participants are then identified that can best assist in understanding the central event. Permission from the participants and their supervisors are then required because they will be interviewed or observed. Once approval has been given, the interviews or observations can be conducted to collect data to help answer the research questions. In qualitative research, the participants selected are those who can help best understand the phenomenon of the study, rather than randomly selected individuals (Creswell, Qualitative Research Characteristics, 
2008, p. 16). Qualitative research is also the best-suited method for addressing topics such as adult ASD when not a lot of information is known yet or needs to be explored.

Execution of the project was based on the qualitative method known as phenomenological research. Phenomenological research involves identifying the "essence of human experiences about a phenomenon as described by participants" (Creswell, Qualitative Strategies, 2008, p. 13), but also in this case the caregivers as well. This method involved studying a small number of subjects through separate user tests to establish certain patterns and connections of significance. This methodology was used because it allowed the application to be built to suit specific needs of individual participants, rather than just the general needs of larger groups of people as ASD can affect people differently.

\section{Initial Sketches}

It was important to establish what the user and their caregiver would need to begin designing the application. As visuals are a key feature for the user with ASD, discovering how these would be implemented, and look in the application was also important.
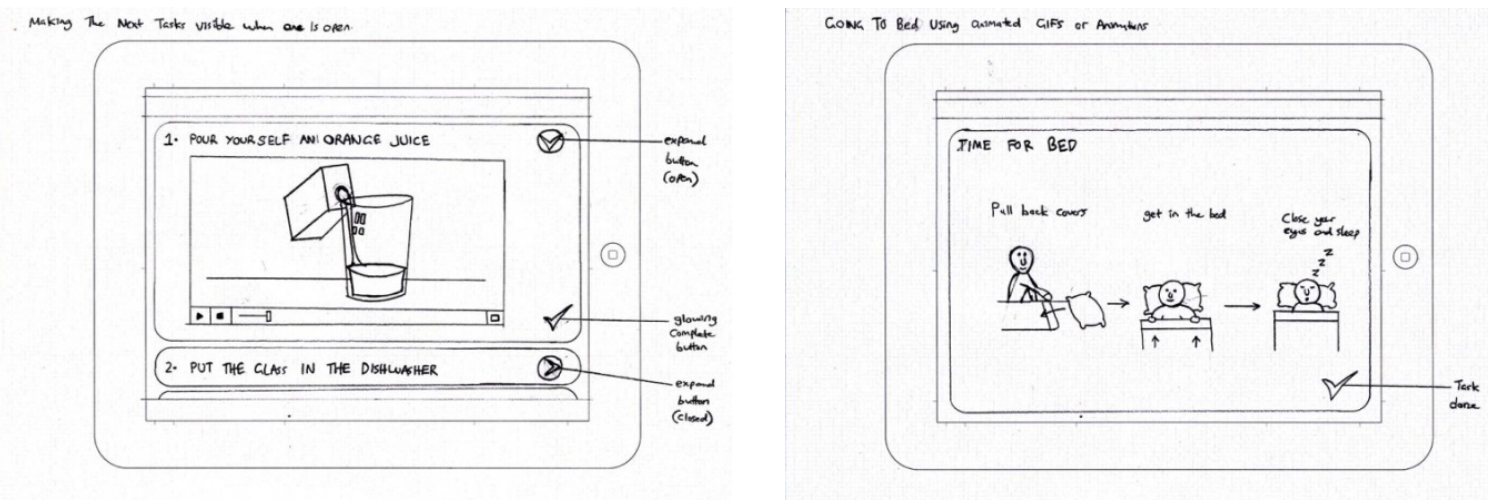

Figures 6-7: template sketches of different tutorial layouts in landscape mode
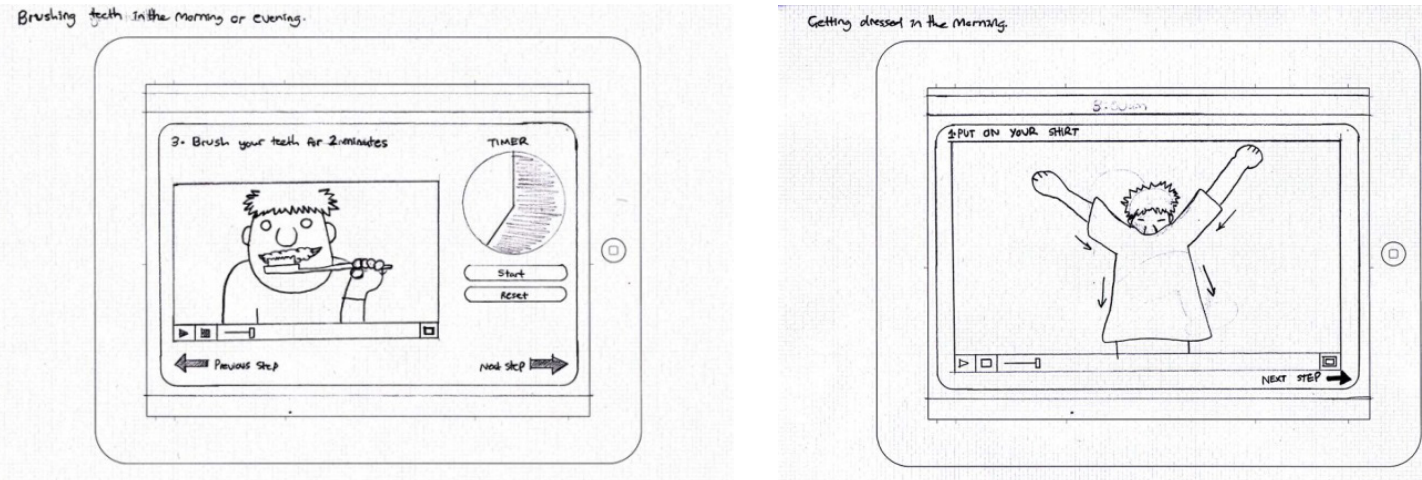

Figures 8-9: more template sketches of different tutorial layouts in landscape mode

To begin the design process, iPad screen templates were used to sketch out the things that would be useful to both the caregiver and the user of the application. The main functions that focused on were the ways to display the visual elements of the application. These included video demonstrations, as well as single images in viewing windows. These took up most of the screen real estate. The reason for selecting this particular layout was to remove objects on the screen that could be detracting from what was the main focus, those being the task demonstrations. Also, how these tasks could be listed within the application was considered. The initial idea was to lay them out like tabs that could be expanded by clicking on them to view the tasks in-depth information. This feature again was about highlighting the areas of the 
screen to focus on when required. The visuals were made the main focus of these sketches because of their importance to teaching people with ASD. This links back to both Temple Grandin, and Susan Dodd's books. They both stated the importance of visuals in learning because it helps the user with ASD more easily understand what they are expected to do.
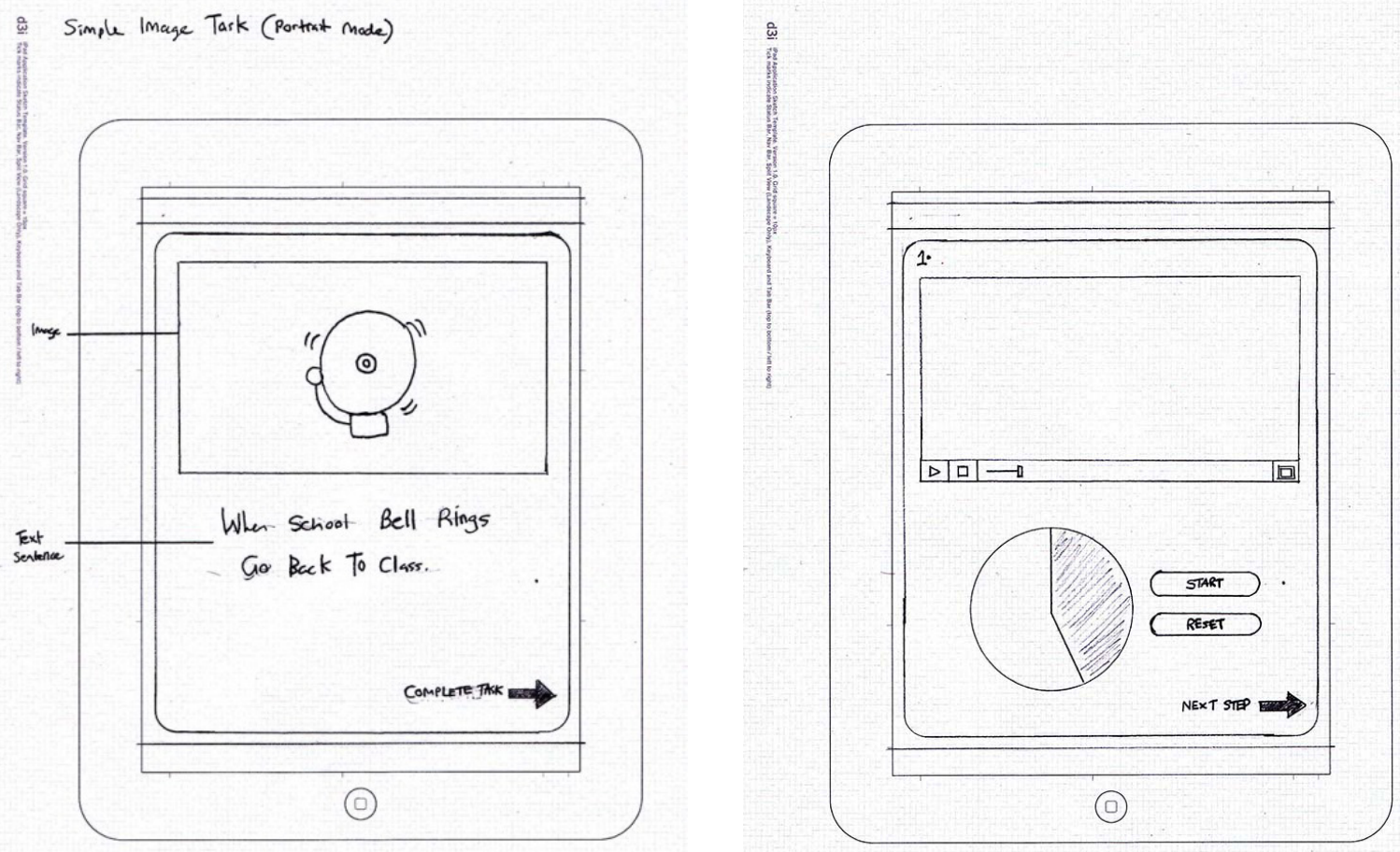

Figures 10-11: template sketches of tutorial layouts in portrait mode
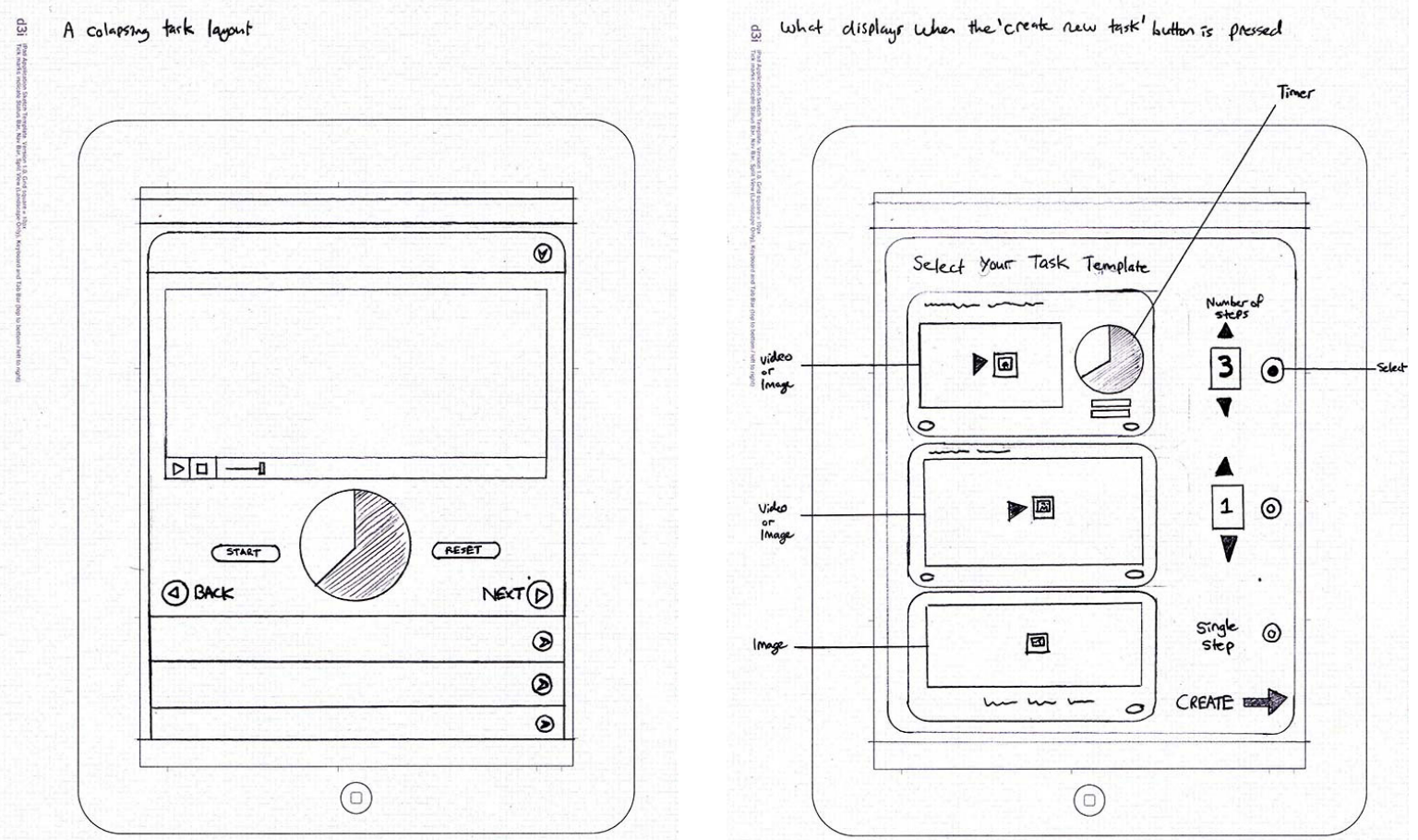

Figures 12-13: more template sketches of tutorial layouts in portrait mode 


\section{Design 1}

For the first design of the application, the layout contained a number of simple features based on the initial template sketches. The first feature was a login screen. The caregiver would create an account and then log into to manage the user's tasks. This feature was included because it allows the application to be operated by both the user and caregiver on different devices. This feature also allows the caregiver to monitor the user's progress with getting tasks done, which could be useful in a situation where the caregiver is at work for the day.

Another feature was the main list of tasks. The way these tasks were displayed was basic but each of these would contain an accordion system that would allow the task information to be viewed or minimized. The task information was set up as a bunch of steps that could be stepped through by previous and next buttons located at the bottom of each step's viewing window. It was important in the process of design 1 to figure out what the user and caregiver would be doing with this application. This was so any confusion over the use of the organizer could be eliminated. For example, the caregiver would be required to progress through setup screens in order to submit a task to the user's to-do list. The user would then be required to follow the tutorials provided to complete those tasks. For the caregiver side, a group of setup screens were displayed as a group of steps with inputs to submit text, images, or video. The reason the caregiver was allowed to make the tutorials themselves was based on the 'Children's responses to the image of self, peer 'experiment (Wakako Sanefuji, 2011). The allowing of the caregiver to create the tutorials meant that if the user responds better to a family member demonstrating how to do something, that can be provided for them. The user would view the created tasks, read the step descriptions, and then follow the video or image demonstrations to complete them.

The layout of task tutorials in this design was based off an initial sketch. This sketch involved three features. The first was a visual (video or image), second being a text description of this step, and thirdly an optional timer if required. Focusing on the timer for a moment, this was shaped like a pie or a pizza with segments removed as it is eaten. In the case of this timer it goes in reverse and fills up instead. This form of timer was selected because it is a visual representation of time. Furthermore this type of timer is less likely to cause the ASD user anxiety like a digital timer. People with ASD can become anxious frequently compared with someone without the disorder. In the book 'Mental Health Aspects of Autism and Asperger Syndrome' Mohammad Ghaziuddin expresses that the

Symptoms of anxiety are often described in persons with ASD. People across the entire range of pervasive development disorders (PDDs) may present with these symptoms although they are more often reported by those who are higher-functioning and those with Asperger syndrome, probably because of their better-preserved verbal skills (Ghaziuddin, p.149, 2005).

When a digital timer is presented to an ASD user, it could begin to make them anxious as they watch the numbers counting down. A slowly filling timer is a better way of representing seconds or minutes. This is because it does not give the same daunting effect to the user, or draw as much of their attention away from the task to be completed. 


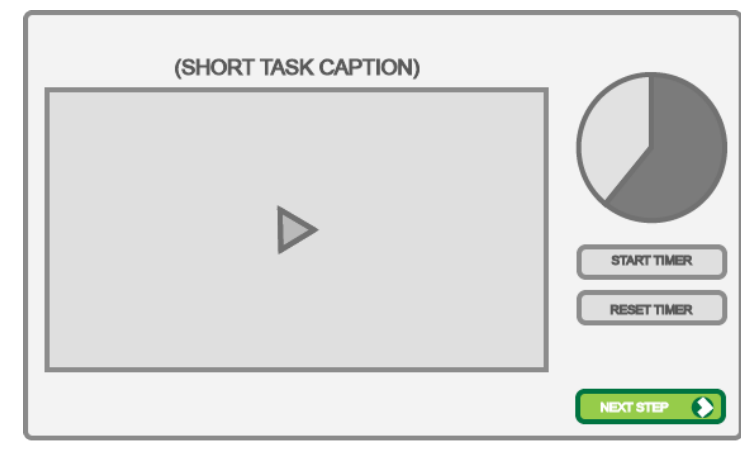

TEMPLATE 1: VIDEO AND TIMER

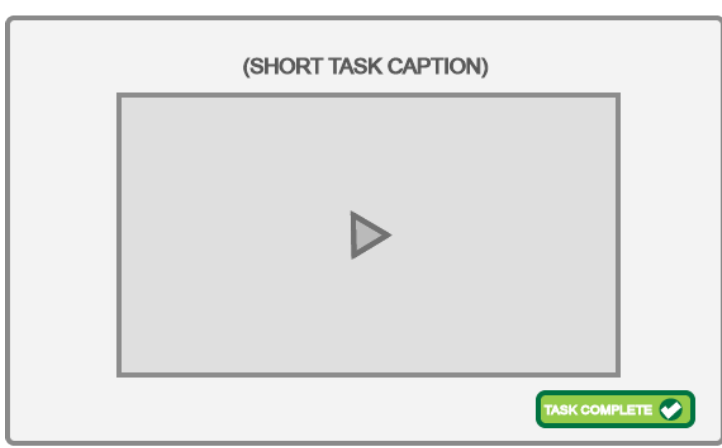

TEMPLATE 2: VIDEO

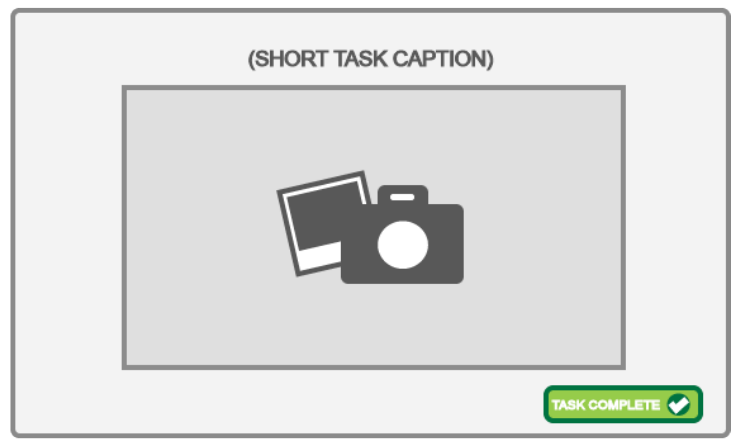

TEMPLATE 2: IMAGE

Figure 14: caregiver setup options for design 1

BRUSH YOUR TEETH FOR 2 MINUTES

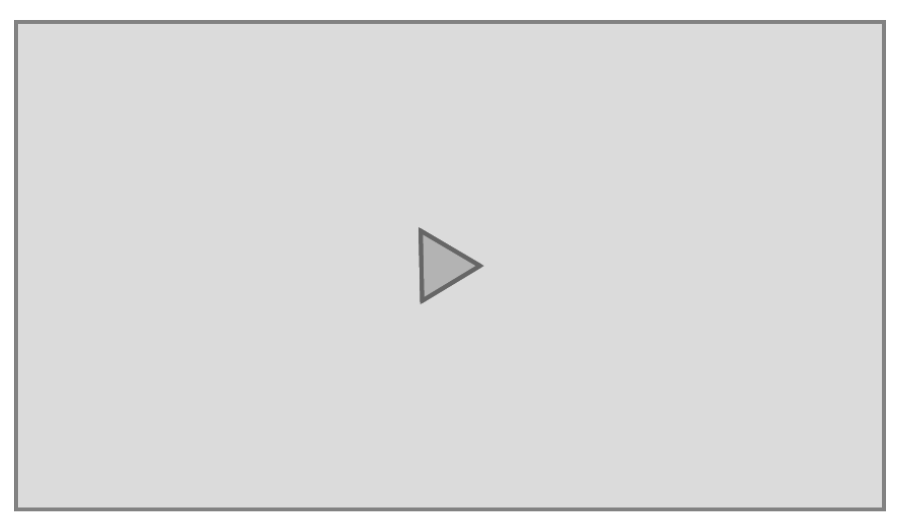

PREVIOUS STEP

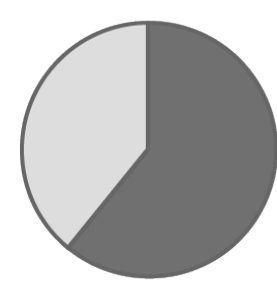

START TIMER

RESET TIMER

Figure 15: user tutorial layout including a video placeholder, and pie timer

\section{Design 2}

For the second iteration of the application, the focus was on improving the layout as well as selecting the colour palette.

With this particular design the layout remained a list with visual demonstrations within each item, only this time the items would become a checklist. This feature was decided on because it allowed the user to mark off what they had done. It also allowed the caregiver to see what had been completed and what was still left to do.

This design also included a drag-and-drop system for taking and placing tutorials or timers from a side panel, or overlaid library into a task in the checklist. The idea was that a caregiver 
could take for example, a video tutorial they had made for the user and drag it into a list item they had set up in the checklist. The caregiver would have the ability to generate guidance tutorials and have them stored in the application so they could be placed in the list when needed. This feature was created to save the caregiver time, rather than having to reimport images or videos into the application every time the task needs to be added to the checklist.

The name selected for this application was manage me. This name was selected because it represented self-management of individualized tasks. The use of the word "me" also emphasized that the application caters to the user, so it is personalized for them.

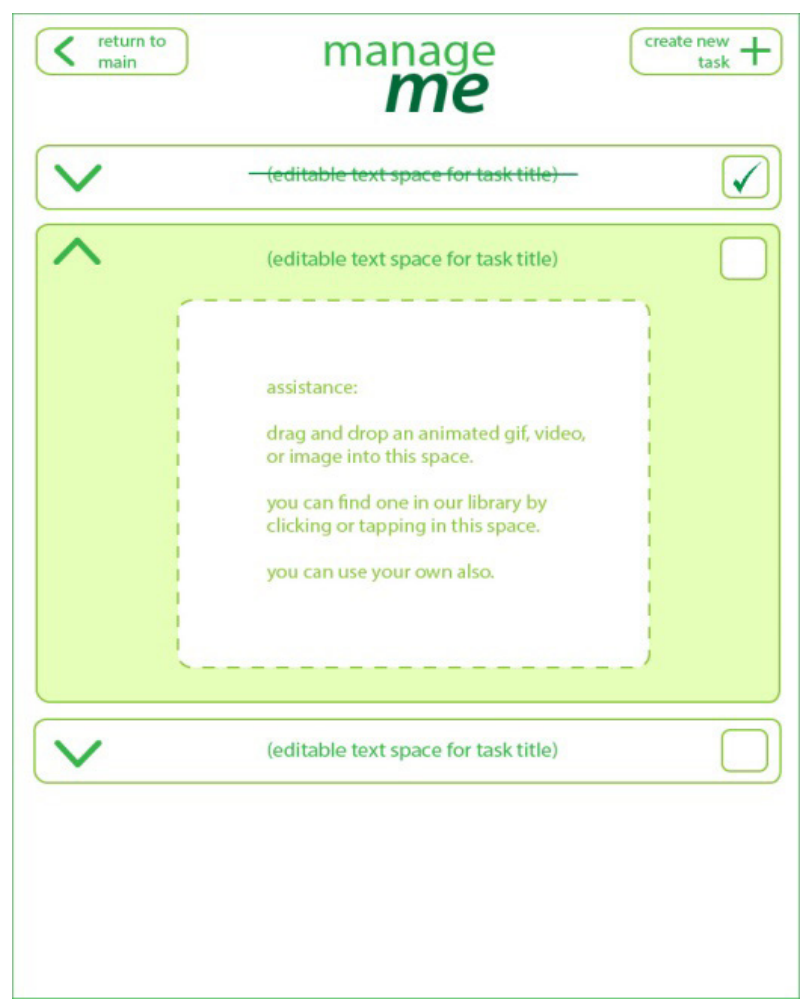

Figure 17: design 2 expandable drop zone for dragand-drop visuals in landscape mode

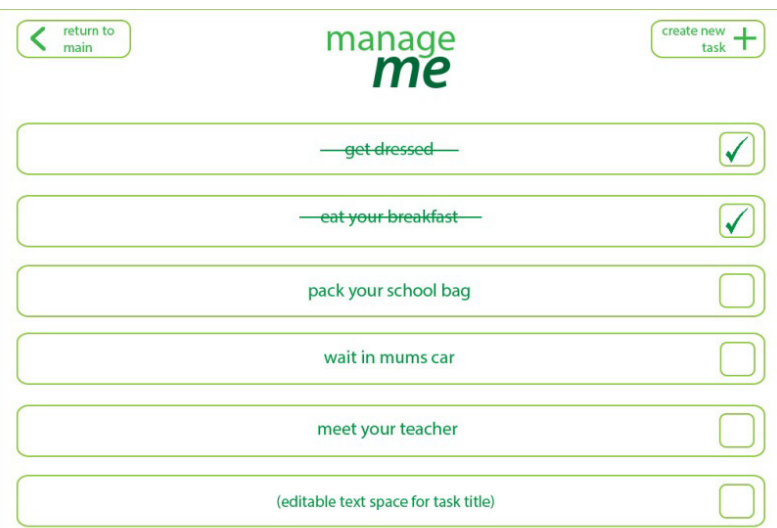

Figure 16: design 2 checklist system with standard text list

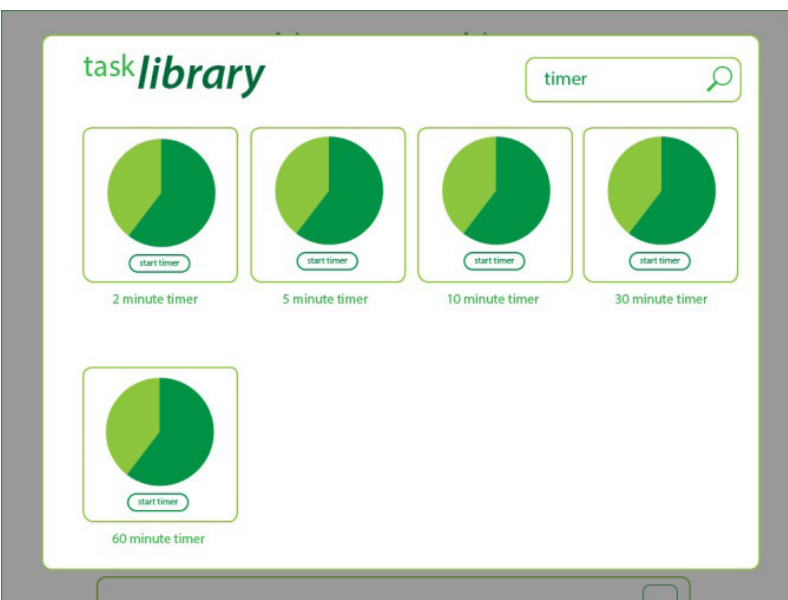

Figure 18: selection of draggable timers for the drop zone 


\section{Design 3}

The third design iteration took a lot of features from design 2 and improved on them. These included:

- The checklist receiving more viewing options.

- A new input area at the head of the checklist for adding text tasks.

Tabbed sliding panels for storing and managing the drag-and-drop visual tasks.

- Sliding panel for a settable timer also.

A new name for this application was given. The name was changed from manage me to rmindr. This name was selected as a different take on the word reminder. This name was chosen because reminding the user about tasks or tutorials is the applications main objective. This name was also chosen in favour over manage me because the name is more abstract and less literal.

To assist both the user and caregiver more with viewing of the tasks, some filter buttons were added to the footer of the interface. The filters allowed what was needed to be seen by either user or caregiver. The 'All' button displayed both checked and unchecked tasks. The 'Active' button only displayed unchecked (uncompleted) tasks, and the 'Completed' button displayed only checked (completed) tasks. These were incorporated into the design because the user may only need to see tasks left to be completed, while the caregiver may only want to see what the user has finished on their checklist.

Also, included was a number indicator that displayed the number of uncompleted tasks remaining in the checklist. This feature was chosen because indicating to the user how many tasks were left to complete, gave them some reassurance that they have a set number to complete, without there being any unwanted surprises. An early discovery in the project revealed a couple of useful notes with displaying visuals within the guidance tutorials. The first thing was that using single photographs for each step of a task did not display enough information to the user. A photograph is static and does not show the different movements that may be required for doing things, such as opening a bottle

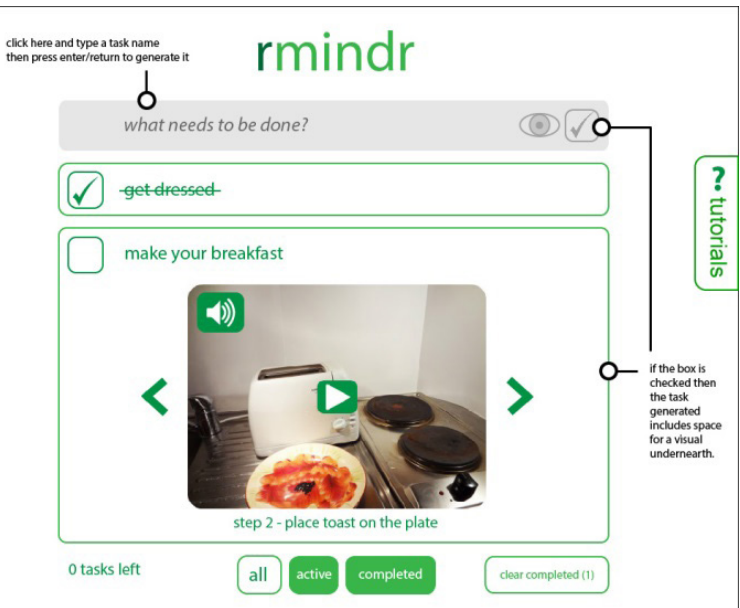

Figure 19: main interface of design 3

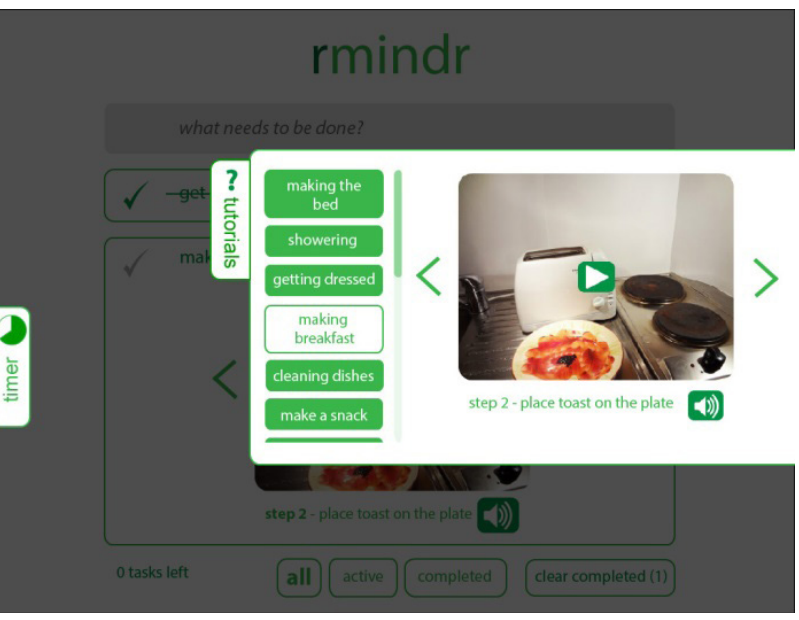

Figure 20: tutorials panel containing draggable demonstrations

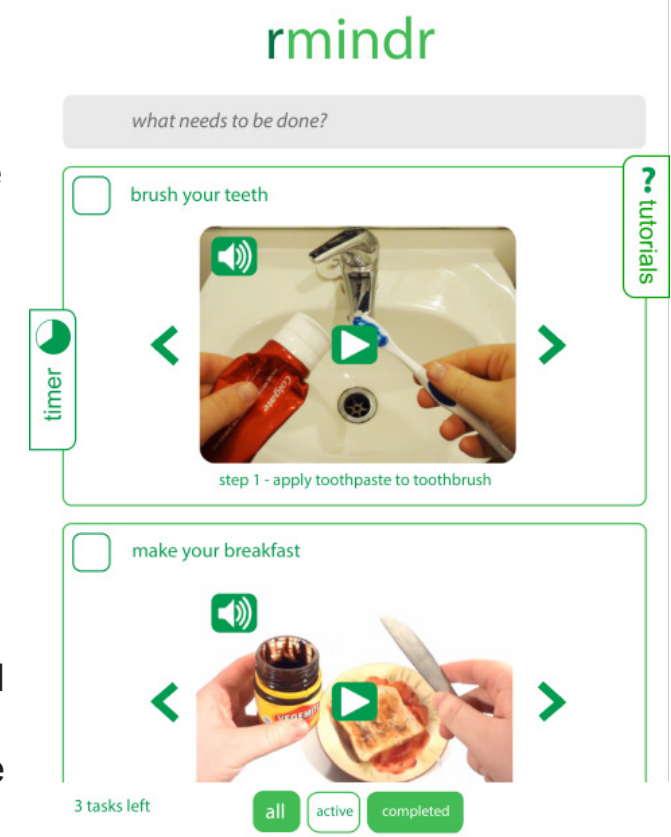

Figure 21: rmindr with visual tasks added to the checklist 
of soft drink for example. It would have made sense to use video instead to solve the problem. Nevertheless, when a group of video tutorials were filmed it became clear that each step took a minute or more to complete which used up a lot of time. This relates back to the experiment on perceptual load. Anna Remington said that people with ASD already get distracted quite easily, so If each visual in the tutorial takes a long time to view, the user may lose interest and get side tracked by something else (Anna Remington, 2009, p. 1392).

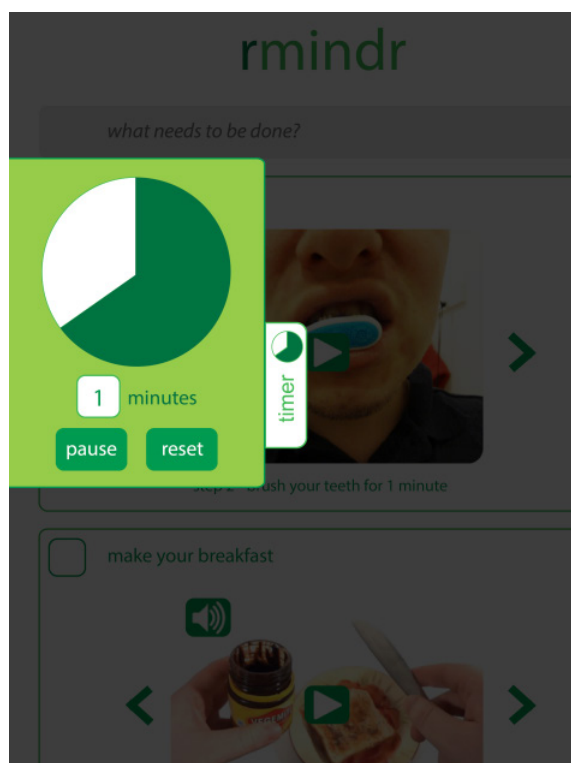

Figure 22: settable timer panel when displayed

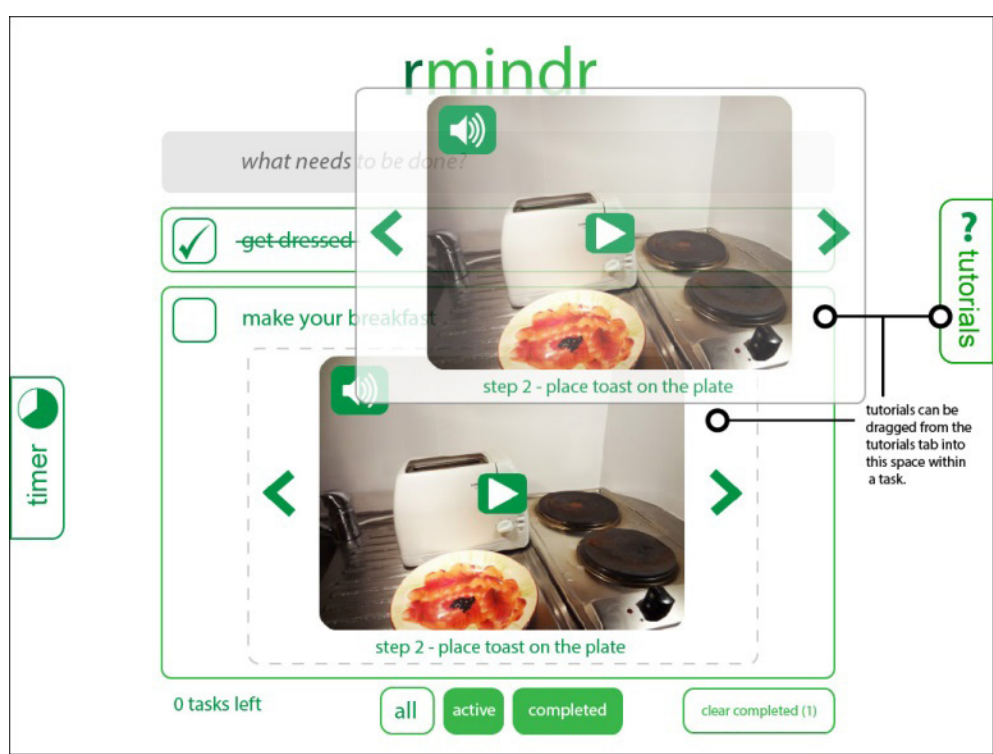

Figure 23: dragging a tutorial into a visual task

\section{Design 4}

For the fourth iteration of the application, most of the features in design 3 were improved upon by simplifying them and the layout.

One of design 4's new features is a switchable caregiver/user mode. An invisible button located on the task counter allowed certain features of the application to be turned off or switched on. For example, access to the tutorials panel and viewing filters would be removed so the user does not fiddle with the caregivers' setups, or can cheat by removing tasks from the completed list themselves.

The tutorial side panel from design 3 was replaced with a panel that slides up from the footer. To access the new panel, a toggle button was placed in the right corner of the footer. Initially the tutorials remained the same as in design 3. It had been noted that the tutorials that had been dragged into the checklist did not seem to flow alongside the items that had been text inputted. If the checklist had a number of items in it, it made concentrating on the tutorial steps difficult because everything else around it was still in view also. The solution actually came from design 1 . This was

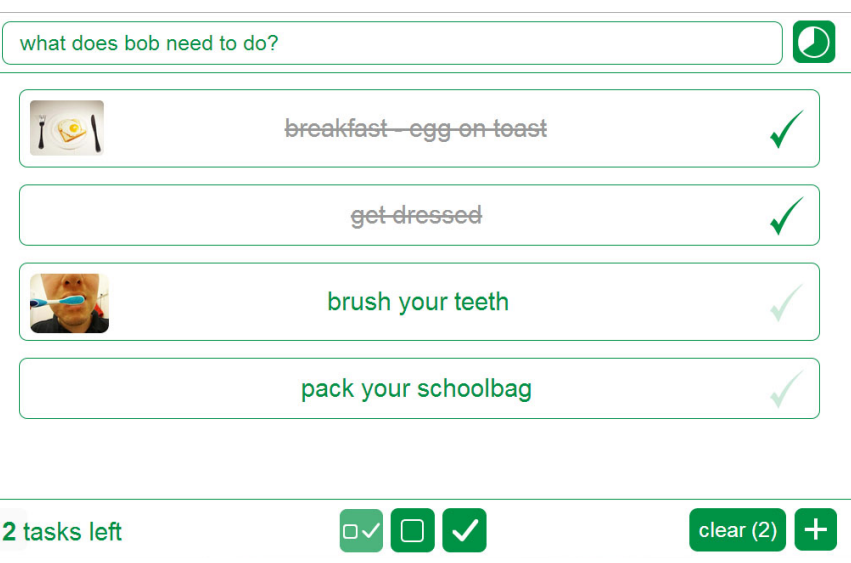

Figure 24: design 4 interface in caregiver setup mode 
to place the tutorial in a window that uses most of the screen real estate. This window was opened by clicking a thumbnail button on the visual task. This solution was an improved design as it draws the users focus in on the tutorial without any other distractions around it. The tutorials are navigated by left and right arrow buttons.

The tutorials have three features;

- Stop-motion videos

- Step descriptions

- Optional timer if required

The stop-motion videos use a sequence of imported images. The images step though giving the user a quick example of the processes to complete a step. Using this technique greatly speeds up the process of viewing a demonstration without unnecessary features or distractions. This section of the panel could also use a single image instead, for example; the step is the result of a cooking tutorial (the final product). The second feature is a short text description of what is taking place in the stop-motion video or single image. The third feature is an optional preset timer. The preset timer is for tasks that might require a waiting or doing time in one of the steps. This would be helpful for someone brushing his or her teeth for 1 minute, or letting food stand for 2 minutes after cooking is complete. This timer is also preset to remove any input fields from the task so the user does not change the duration by accident or out of curiosity.

To simplify the interface further, the text on the viewing filter toggles was replaced with icon symbols. This was implemented because when the iPad screen would transition from landscape to portrait mode, the footer appeared cluttered. Replacing the text with symbols separated the filters enough from the other footer features.

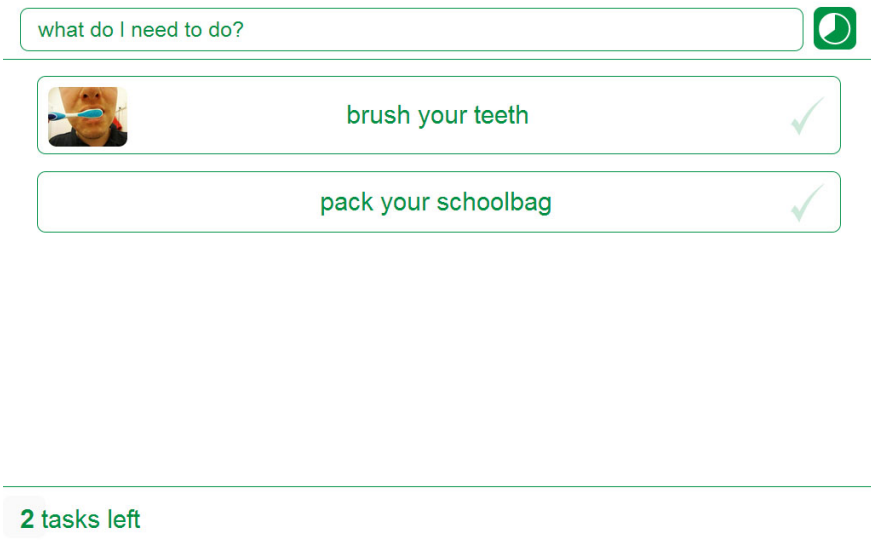

Figure 25: design 4 interface in user mode

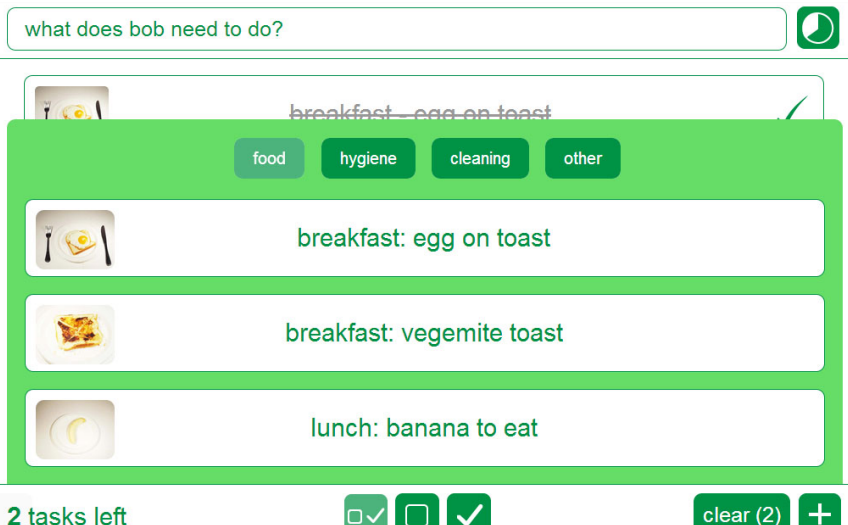

Figure 26: tutorials panel in design 4

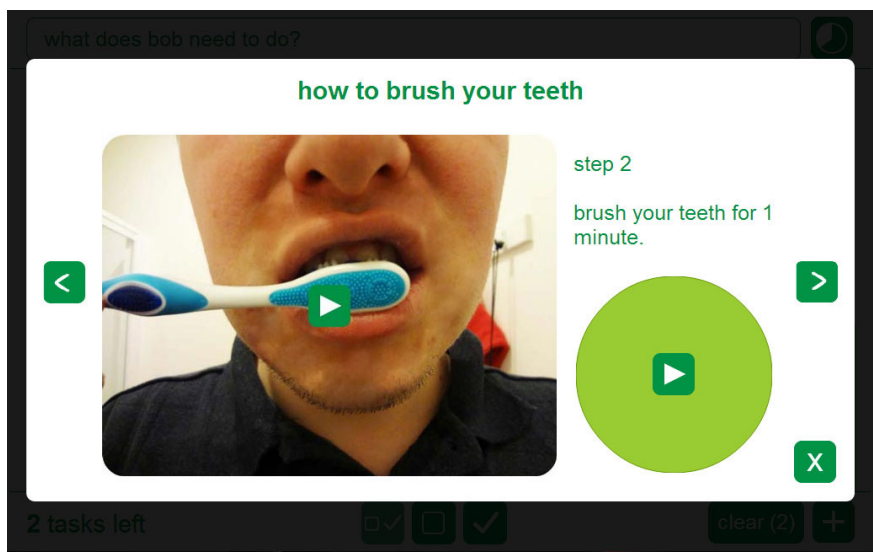

Figure 27: tutorial full screen with stop-motion video, description, and preset timer 


\section{The Participants for the project}

As the method used for this project is phenomenological research, only a small group of participants is required. This is because it involves studying a small number of subjects through extensive and lengthy engagement to establish certain patterns and connections of significance. This method was used because it allowed building of the application to suit specific needs of individual participants rather than just general needs of larger groups of people. However, this method would also help in figuring out features for the application that work for all the individuals as a whole.

\section{Overview of Participants}

All of the participants are between the ages of 12 and 25. It seemed from the initial meetings that the youngest teenagers with autism needed the most help with managing themselves. Older participants generally only need occasional reminders, as they have already mentally created routines for themselves.

\section{User Tests}

The user testing done with participants and caregivers produced positive results:

\section{Participant 1 (20 years old)}

To begin, he was shown how the application worked and what he would be doing with it. He understood that he could add his own list items by typing into the header bar and clicking the return key to add them. He also clearly understood that when he clicked the checkboxes to mark the items as complete he was finished with the task.

Participant 1 found the timer useful because he could set it up himself. He stated that it would be very useful to him in the case of tasks where he had to wait for specific amounts of time before proceeding onto something else. He liked the green and white colour choices and layout of the application; saying "It's simple" and not confusing like other management software he has used previously.

When Participant 1 was shown the visual tutorials incorporated into the application, he was immediately curious to know if more cooking tutorials could be added to the application. He was reassured that if it was in its production form, his caregiver could create additional cooking tutorials.

\section{Caregiver of Participant 1}

The caregiver of participant 1 liked the possibility, if the application was further developed, she would be able to add things for participant 1 to do at home when she is away at work for the day to keep him busy. She also stated that an application like this would be of great use in special needs classrooms where multiple students are required to follow a set of instructions. She believed based on her experience with Participant 1 that visual instructions such as those in the application would be of great benefit to them and others such as teachers.

\section{Participant 2 (12 years old)}

From both an account from Participant 2's caregiver and meeting the user in person it was clear they had a tendency to become anxious and stressed easily. This user was also very self-ware of when he may have been bothering people because he liked to sing to himself.

Like with Participant 1, Participant 2 was shown with his caregiver all the features of the application they would be using. Participant 2 was able to navigate the application without any issues. When he opened one of the cooking tutorials, he understood 
without anybody telling him how to view the stop motion video tutorials. He navigated through the steps of the tutorial, viewing each tutorial with concentration and amusement.

\section{Caregiver of Participant 2}

Participant 2's caregiver believed the application would be useful to them. She said that Participant 2 had recently learned how to tell time in both analogue and digital. She said that he was use to using "time timers" which use red as their colour of choice. She believed the timer in the application was better because it used green instead of red because of a practice often taught in special needs classes, the practice known as traffic light instructions.

\section{Participant 3 (25 years old)}

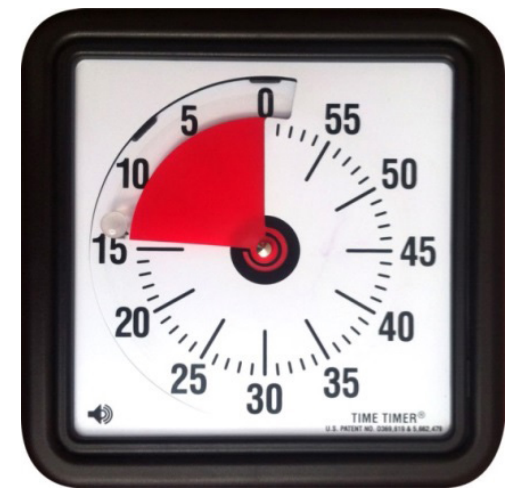

Figure 28: time timer

Participant 3 is the oldest of the group of user tests. Demonstrated to him and his caregiver were all the features that both of them would be using. Participant 3 was curious as to whether the colours of the application could be changed. He said he would like a black and white colour scheme rather than green. He was reassured that while interface colour choices were not currently and option of the application, they would be incorporated it into future iterations because it is a valid point that would further personalize the application to the users taste. Personalizing the application more through colour customization would help users of the application feel more comfortable using it.

Participant 3 also wanted to know if the application in the future could read out text aloud such as the steps for the tutorials. He believed this would help him greatly as he prefers to hear and see a tutorial rather than struggle to read it. Recording speech into the tutorial steps would also add personalization if for instance the user responds better to their caregivers voice than someone else's.

Both Participant 3 and his caregiver liked the drag \& drop feature. They thought it was a nice interactive addition to the application. They also liked the fact that items added to the checklist could be rearranged if needed.

Participant 3 also believed that the timer would be useful to him, though he believed that optional ringtones should be available for when the timer completes a cycle. Like Participant 1 he was keen on this feature because he wanted to have the freedom to choose what sound he liked.

\section{Caregiver of Participant 3}

The caregiver was surprised that participant 3 was engaged and interested in the application. She said this was unusual for him. For me this further indicated that the project is of good interest to the autistic community because it is aimed to their lives easier, rather than just making the caregiver's life easier without giving any control to the user. 


\begin{tabular}{|c|c|c|c|}
\hline Participants & 1 & 2 & 3 \\
\hline $\begin{array}{l}\text { ‘Drag and drop' fea- } \\
\text { ture was useful }\end{array}$ & Yes & Yes & Yes \\
\hline $\begin{array}{l}\text { ‘Timers' } \\
\text { feature was useful }\end{array}$ & Yes & Yes & $\begin{array}{l}\text { Somewhat } \\
\text { Was useful but not } \\
\text { something they } \\
\text { needed. }\end{array}$ \\
\hline $\begin{array}{l}\text { Liked colour of the } \\
\text { interface }\end{array}$ & Yes & Yes & $\begin{array}{l}\text { No } \\
\text { Preferred to be } \\
\text { able to select their } \\
\text { own interface } \\
\text { colours. }\end{array}$ \\
\hline
\end{tabular}

Figure 29: Comparison of User Testing 1 participants' reactions to application features

\section{Second user tests}

User tests were conducted for a second time to see if any new discoveries would reveal themselves. The same three participants and their caregivers were used for the tests. This time the focus was on seeing if the autistic users could follow the tutorials provided in the application. The other focus for the second round of user testing was to see how well the caregivers would be able to set up a visual tutorial for the participants. For the test the caregiver was asked to follow the steps to set up a tutorial in the tutorials panel. The setup screens were laid out as a group of text inputs and upload buttons, similar to those found in internet registration forms.

\section{Participant 1 and Caregiver}

Participant 1 had no trouble following the tutorials preset in the application. He reemphasized the idea that his meals being laid out as tutorials for him to follow excited him. He felt confident from following the tutorials that he would be able to do more things around the house by himself.

For the tutorial setup options though, participant 1's caregiver was a little confused as to what each input was generating. It appeared from this observation that the caregiver had to work blind through each setup option. It was agreed upon that there needed to be previews of what was being generated as items are inputted. A preview viewer would eliminate a lot of confusion around the setup options and give a much clearer path to outputting the result. This issue was later discussed with participant 2 and 3's caregivers. They also agreed that there needed to be a way of viewing what each input was doing, as it was being completed.

\section{Participant 2 and Caregiver}

Participant 2 was asked if he would be interested in completing the cooking tutorial for making a fried egg. This tutorial was included in the application based on a recommendation from participant 2's caregiver to learn. 
The test was conducted separately from the meeting by participant 2 and their caregiver so that the environment for both of them would be more natural. This way of testing also meant the test would be conducted as if it were a normal routine. Participant 2 seemed puzzled when asked if he would like to do the tutorial as part of his lunch. He asked "why do I have to do it?" and did not seem to see the point in doing the tutorial as he did not eat eggs very often for meals. This observation reinforces the need for the applications tutorials to be made to suit the user.

Because the tutorials in the application were preset and designed by someone other than the user's caregiver, it can be difficult for the user to see the relation between them and the task. This point relates back to the analysis of applications already on the market. Nearly all of them had their visuals premade by a developer. These would have been decided upon to save the caregiver time preparing the users schedules, but they actually demonstrate a flaw in the logic behind them.

A caregiver knows their son or daughter with ASD better than anyone else so it would make sense that they construct the tutorials. An autistic user needs customization in the application so they can feel it is specifically for them and not just a general audience.

Participant 2 did eventually follow the tutorial with their caregiver. The caregiver reported that they did not have any problems following the tutorial which is a positive result.

\section{Participant 3 and Caregiver}

Participant 1 said that following the tutorials was quite easy for them. They liked the clear and easy to read appearance of the application. They really aspirated that there were no distractions around the screen such as advertisements (commonly found in other applications).

One thing they thought was confusing was one of the stop motion videos that displayed the ingredients to cooking a fried egg. The ingredients were displayed in groups of two as the short video plays. They believed every ingredient should be displayed separately to eliminate any confusion as to what item is what. This comes back to the difficulty of breaking down tasks into logical steps. A task can continuously be broken down into smaller units but a lot of thinking has to be done to cover all the possible problems or options that could arise.

This participant and their caregiver also noticed a problem that could quickly arise when it comes to naming of objects in a tutorial. They noticed in the egg cooking tutorial that the term "fish slicer" was used to name the spatula utensil. To them this caused some confusion because the use of the word "fish" in an egg cooking tutorial did not seem right. This also raised a point about naming of objects. Some objects have multiple names for them, which can become a problem if the user is not familiar with another term for it. This could be an issue if the caregiver calls an object something, while the user refers to it as something else. 


\begin{tabular}{|l|l|l|l|}
\hline Participants & 1 & 2 & 3 \\
\hline $\begin{array}{l}\text { User was able to } \\
\text { follow tutorials }\end{array}$ & Yes & Yes & Yes \\
\hline $\begin{array}{l}\text { Caregiver under- } \\
\text { stood setup screens }\end{array}$ & Somewhat & Somewhat & Somewhat \\
$\begin{array}{l}\text { Understood the } \\
\text { process but could } \\
\text { not see what they } \\
\text { were making due } \\
\text { to there being no } \\
\text { previewer. }\end{array}$ & $\begin{array}{l}\text { Understood the } \\
\text { process but could } \\
\text { not see what they } \\
\text { were making due } \\
\text { to there being no } \\
\text { previewer. }\end{array}$ & $\begin{array}{l}\text { Understood the } \\
\text { process but could } \\
\text { nore mat mang due } \\
\text { to there being no } \\
\text { previewer. }\end{array}$ \\
\hline
\end{tabular}

Figure 30: Comparison of User Testing 2 participants' reactions to application features

A limitation of the user testing is that all the participants were male. This is mainly a result of the fact that the only people that could be sourced for testing. However, this disparity in gender may have been caused by the statistics; the number of boys diagnosed with ASD often outnumbers girls.

Researchers have found ASD is diagnosed four times more often for boys than girls. It has been found that a gene known as CACNA1G, which has been linked to ASD, is more commonly found in boys than in girls however why this is the case is still not clear (Park, 2009). In future user tests female participants would be recruited to improve the generalizability of the data.

\section{Final Design}

The final design took a lot of what was

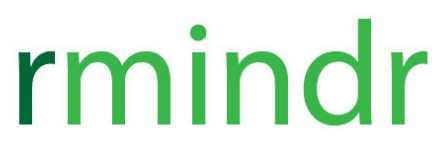
already successful in design four and improved upon it. Most of the new features were conceived from discoveries and recommendations found in the first and second set of user tests. For design five the screen layout remained largely unchanged because it had proved to be an effective layout. The name also remains as rmindr.

One thing that needed to improve over design four was the task setup screens for the caregiver. Design four used a large overlaid panel with sections for the stopmotion video, text description, timer, and audio button. Revisiting this design, presenting the setup inputs in this manner

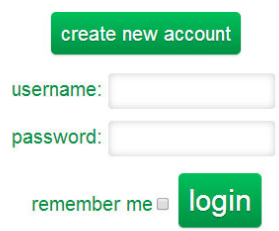

Figure 31: final login screen design

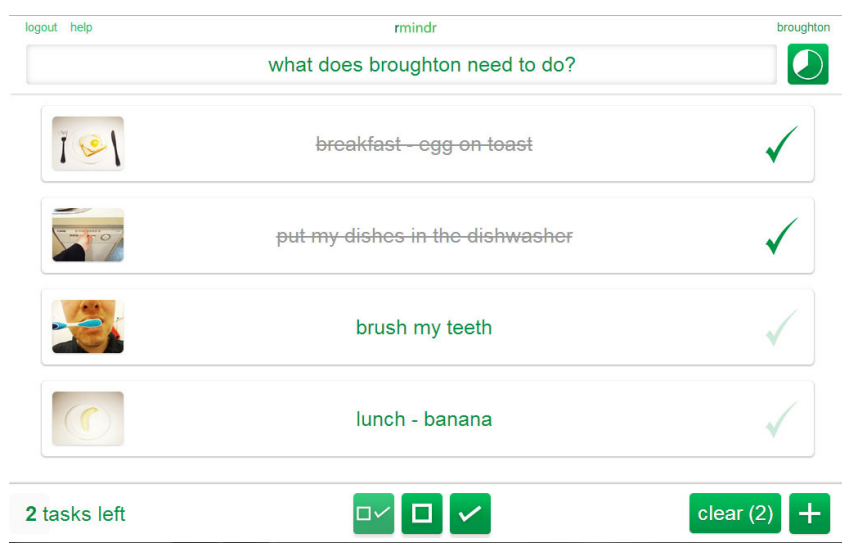

Figure 32: final interface look 
was quite confusing to read and needed to be revised. As humans read things from the top left to the bottom right of a page it made sense for the layout of the setup panels to be the same. To do this the large selectable areas were replaced with smaller input areas for the text, and upload buttons for the images and audio.

To further improve the setup screens. Previews of what the caregiver is building were included in the design. These were introduced into the design so the caregiver does not have to output the tutorial and

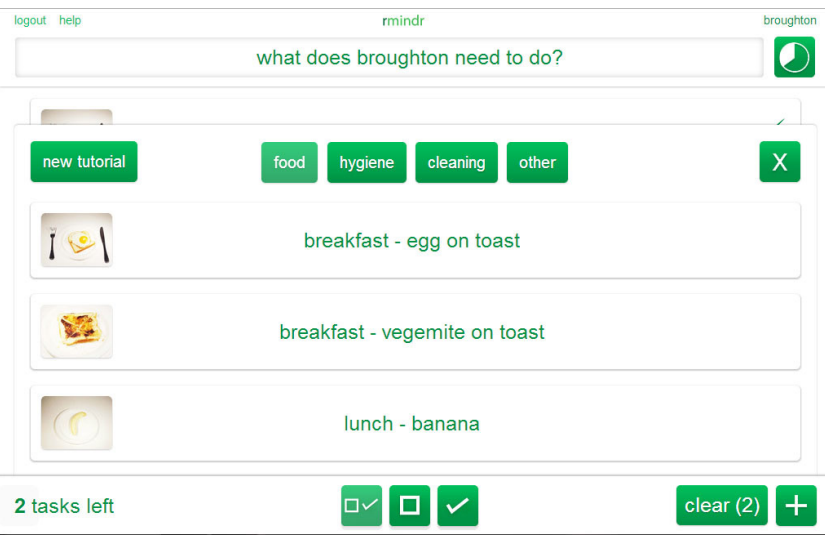

Figure 33: tutorials panel then go back to edit the pieces they may have missed filling in.

Another new feature for this design is time stamps on completed tasks. These are located next to the checkbox on tasks when viewed under the completed tasks filter. The time stamps display what time the task was completed at. This is to indicate to the caregiver if the user is doing their assigned tasks in good time or if they are getting distracted.

A login system was also incorporated into the final design. This system is so the application can be connected between say a user's iPad and their caregiver's computer. The point of this is so the caregiver can update the user's iPad task list when the caregiver is away from them at work as an example. The caregiver can also monitor what the user is getting done on their checklist and what still needs to be completed.
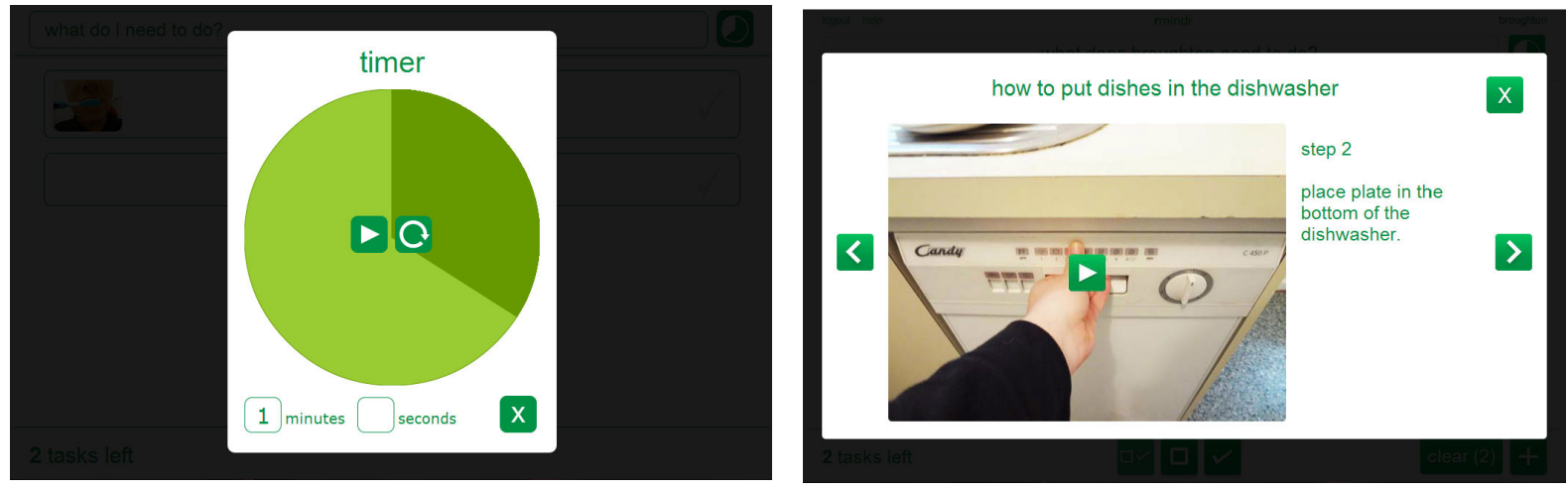

Figures 34-37 (clockwise): settable timer, tutorial, interface colour selector, visual tutorial setup
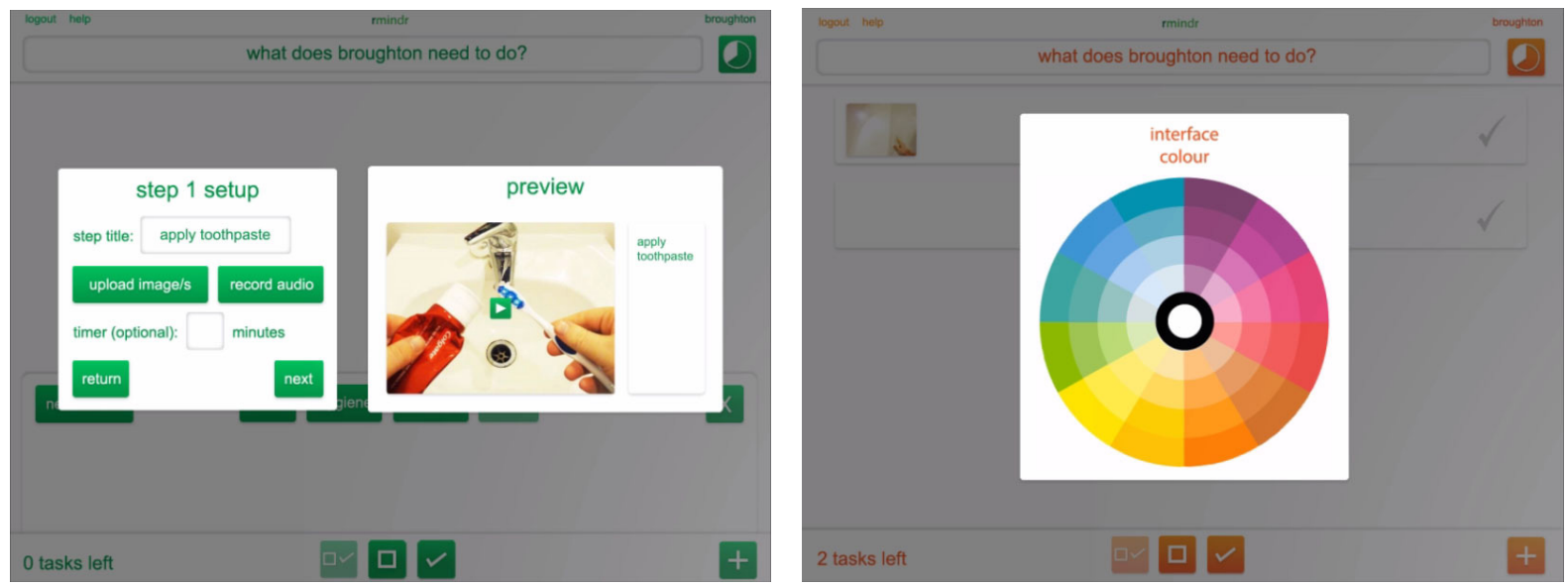


\section{Conclusions}

In summary, the project has spawned positive results and outcomes. The aim of this study was to build a piece of digital media to assist young adults with autism into adulthood. This project has contributed to an area of the ASD community that has not been explored extensively and has addressed the need to do so. The results from the user tests have revealed that a digital personal organiser is perceived as useful by the young adults living with the disorder. While other parties have made small attempts to build applications for people with autism, this research has revealed that there is still too much focus on children and not enough on what happens when they grow up. This project has been a success in that respect because the participants and their caregivers all believed that the application would be useful to them or someone else. By no means is the application as complete as it ever will be. There are many more discoveries to be made to continually improve the application for the autistic community. A project like this is a continuous development that can always be upgraded further, and has proven it can go beyond this project.

It is important that the needs of people who live with ASD are not forgotten about when they are older. These needs simply change. All people wish to become autonomous individuals with the ability to live life on their own terms. This application aids older people who live with ASD in their journey towards independence, without the need for constant surveillance and assistance, so that they too can become self-sufficient and self-ruling adults. After all, in the words of Michel de Montaigne, 'The greatest thing in the world is to know how to belong to oneself'.

\section{Discussion}

This project has revealed that an application such as rmindr is of use to the ASD community. The application proved its effectiveness at assisting young adults with the disorder through the user testing, and all of the caregivers appreciated such a product. Moving forward, it would be great to see $r$ mindr become a commercial product someday. As one of the caregivers stated during the user testing "this product would really benefit teenagers with ASD in school". With iPad's becoming common in schools now, it would be of use to teachers who have to manage a special needs class with multiple students. If the students respond better to visual instructions more than verbal, the teacher could forward the tasks through to all the students' iPad's with rmindr installed. It would be interesting to see rmindr expand to help more and more people. While the focus of this project was on people living with ASD, the application could spawn different versions that could assist other disabilities such as Down syndrome. This project does not end here; it is a stepping stone to even more discoveries about ASD. 


\section{Acknowledgements}

Thank you to:

Kah Chan

Bernard Guy

Vanessa Elliott

Waru and Mairi Wharehoka

Isaac and Karen Glenny

Matthew and Elizabeth Gooch

Daniel Whittington

Octavia Palmer

Lily Shen

Benjamin Richards 


\section{Bibliography}

Bradford, W. C. (2011). Reaching the Visual Learner: Teaching Property Through Art (SSRN Scholarly Paper No. ID 587201). Rochester, NY: Social Science Research Network. Retrieved from http://papers.ssrn.com/abstract=587201

Brandenburg, L. (2009). One Child with Autism: Why A One-Size-Fits-All Approach Doesn't Work in Autism Education | Kennedy Krieger Institute. Kennedy Krieger Institute. Retrieved February 8, 2014, from http://www.kennedykrieger.org/potential-online/ potential-spring-2009/one-child-autism-why-one-size-fits-all-approach-doesnt-workautism-education

Brandon, J. (2011, March 9). Is the iPad a "Miracle Device" for Autism? FoxNews.com. Text. Article. Retrieved January 2, 2014, from http://www.foxnews.com/tech/2011/03/09/canapple-ipad-cure-autism/

Brasher, J. (2013, November 12). iPads help late-speaking children with autism develop language. Vanderbilt University. Retrieved February 27, 2014, from http://news. vanderbilt.edu/2013/11/ipads-autism-language/

Creswell, J. W. (2003). Research Design: Qualitative, Quantitative, and Mixed Methods Approaches. SAGE.

Dodd, S. (2005). Understanding Autism. Elsevier Australia.

Ghaziuddin, M. (2005). Mental Health Aspects of Autism and Asperger Syndrome. Jessica Kingsley Publishers.

Grandin, T. (2006). THINKING IN PICTURES: Autism and Visual Thought. Retrieved December 1, 2013, from http://www.grandin.com/inc/visual.thinking.html

Grandin, T. (2009). How Does Visual Thinking Work in the Mind of a Person with Autism? A Personal Account. Philosophical Transactions: Biological Sciences, 364(1522), 14371442.

Hill, E. L., \& Frith, U. (2003). Understanding autism: insights from mind and brain. Philosophical Transactions of the Royal Society of London. Series B: Biological Sciences, 358(1430), 281-289. doi:10.1098/rstb.2002.1209

Hua, X., Thompson, P. M., Leow, A. D., Madsen, S. K., Caplan, R., Alger, J. R., ... Levitt, J. G. (2013). Brain growth rate abnormalities visualized in adolescents with autism. Human Brain Mapping, 34(2), 425-436. doi:10.1002/hbm.21441

information overload noun - definition in the British English Dictionary \& Thesaurus Cambridge Dictionaries Online. (2013). Retrieved January 27, 2014, from http:// dictionary.cambridge.org/dictionary/british/information-overload

Johnston, M. (2012, November 20). Study aims to unlock mysteries of autism. New Zealand Herald. Retrieved from http://www.nzherald.co.nz/nz/news/article.cfm?c_ id=1\&objectid=10848645

L2V4bGlicmlzL2R0bC9kM18xL2FwYWNoZV9tZWRpYS8yNTA4NQ==.pdf. (n.d.).

Laugeson, E. A., Frankel, F., Gantman, A., Dillon, A. R., \& Mogil, C. (2012). Evidence-based social skills training for adolescents with autism spectrum disorders: The UCLA PEERS program. Journal of Autism and Developmental Disorders, 42(6), 1025-1036. doi:http://dx.doi.org/10.1007/s10803-011-1339-1

May, P. (2013, July 5). Apps for helping autistic kids socially and academically. MercuryNews. 
com. Retrieved February 27, 2014, from http://www.mercurynews.com/ci_23606844/ apps-helping-autistic-kids-socially-and-academically

Øhrstrøm, P. (2011). Helping autism-diagnosed teenagers navigate and develop socially using e-learning based on mobile persuasion. The International Review of Research in Open and Distance Learning, 12(4), 54-71.

Park, A. (2009, May 19). A Genetic Clue to Why Autism Affects Boys More. Time. Retrieved from http://content.time.com/time/health/article/0,8599,1899756,00.html

Pelt, J. V. (2008, September). Autism Into Adulthood - Making the Transition. Social Work Today. Retrieved January 27, 2014, from http://www.socialworktoday.com/ archive/090208p12.shtml

Remington, A., Swettenham, J., Campbell, R., \& Coleman, M. (2009). Selective Attention and Perceptual Load in Autism Spectrum Disorder. Psychological Science, 20(11), 13881393. doi:10.1111/j.1467-9280.2009.02454.x

Samson, F., Mottron, L., Soulières, I., \& Zeffiro, T. A. (2012). Enhanced visual functioning in autism: An ALE meta-analysis. Human Brain Mapping, 33(7), 1553-1581. doi:10.1002/ $\mathrm{hbm} .21307$

Sanefuji, W., \& Ohgami, H. (2011). Children's responses to the image of self, peer, and adult: Autism and typical development. Research in Autism Spectrum Disorders, 5(3), 11941200. doi:10.1016/j.rasd.2011.01.006

Szalavitz, M. (2013, February 22). Why Girls May Be Protected Against Autism. Time. Retrieved from http://healthland time.com/2013/02/22/why-girls-may-be-protectedagainst-autism/

Ten Things Every Child with Autism Wishes You Knew. (2012, July 25). Autism Speaks. Retrieved December 1, 2013, from http://www.autismspeaks.org/family-services/toolkits/100-day-kit/ten-things-every-child-autism-wishes-you-knew

Todd, J., Mills, C., Wilson, A. D., Plumb, M. S., \& Mon-Williams, M. A. (2009). Slow Motor Responses to Visual Stimuli of Low Salience in Autism. Journal of Motor Behavior, 41(5), 419-426. doi:10.3200/35-08-042

Tofel, K. C. (2011, July 22). Android vs. iPad: the tablet sales figures that matter. Gigaom. Retrieved from http://gigaom.com/2011/07/22/android-vs-ipad-the-tablet-sales-figuresthat-matter/

Willingham, E. (2013, March 20). Autism Prevalence Is Now At 1 In 50 Children. Forbes. Retrieved January 23, 2014, from http://www.forbes.com/sites/ emilywillingham/2013/03/20/autism-prevalence-is-now-at-1-in-50-children/

Zamfir, B., Tedesco, R., \& Reichow, B. (2012). Handheld "App" offering visual support to students with Autism Spectrum Disorders (ASDs) (Vol. 7383 LNCS). 


\section{Figures}

1. PECs Example [Photograph]. (2013). Retrieved February 3, 2014, from http://www.pecs-canada.com/userfiles/image/PECS\%20151-R\%20Small.jpg

2. Visual Aids Communication Pack [Photograph]. (2009). Retrieved April 4, 2013, from http://www.asdvisualaids.com/asd-communication-pack.html

3. Choiceworks [Photograph]. Retrieved April 4, 2013, from http://www.specialneeds.com/products-and-services/autism/special-needs-app-daychoiceworks

4. Augie AAC [Photograph]. Retrieved April 4, 2013, from http://appfinder.lisisoft.com/app/augie-aac.html

5. Autism Activity Routines [Photograph]. Retrieved April 4, 2013, from http://m.img.brothersoft.com/iphone/589/516824589_padscreen1360x480.jpg

28. Time Timer [Photograph]. Retrieved February 1, 2014, from http:// www.thriveeducationandwellness.com.au/uploads/2/1/2/5/21258634/ s405250133983874563_p8_i1_w800.jpeg 
Appendix

Design Concepts
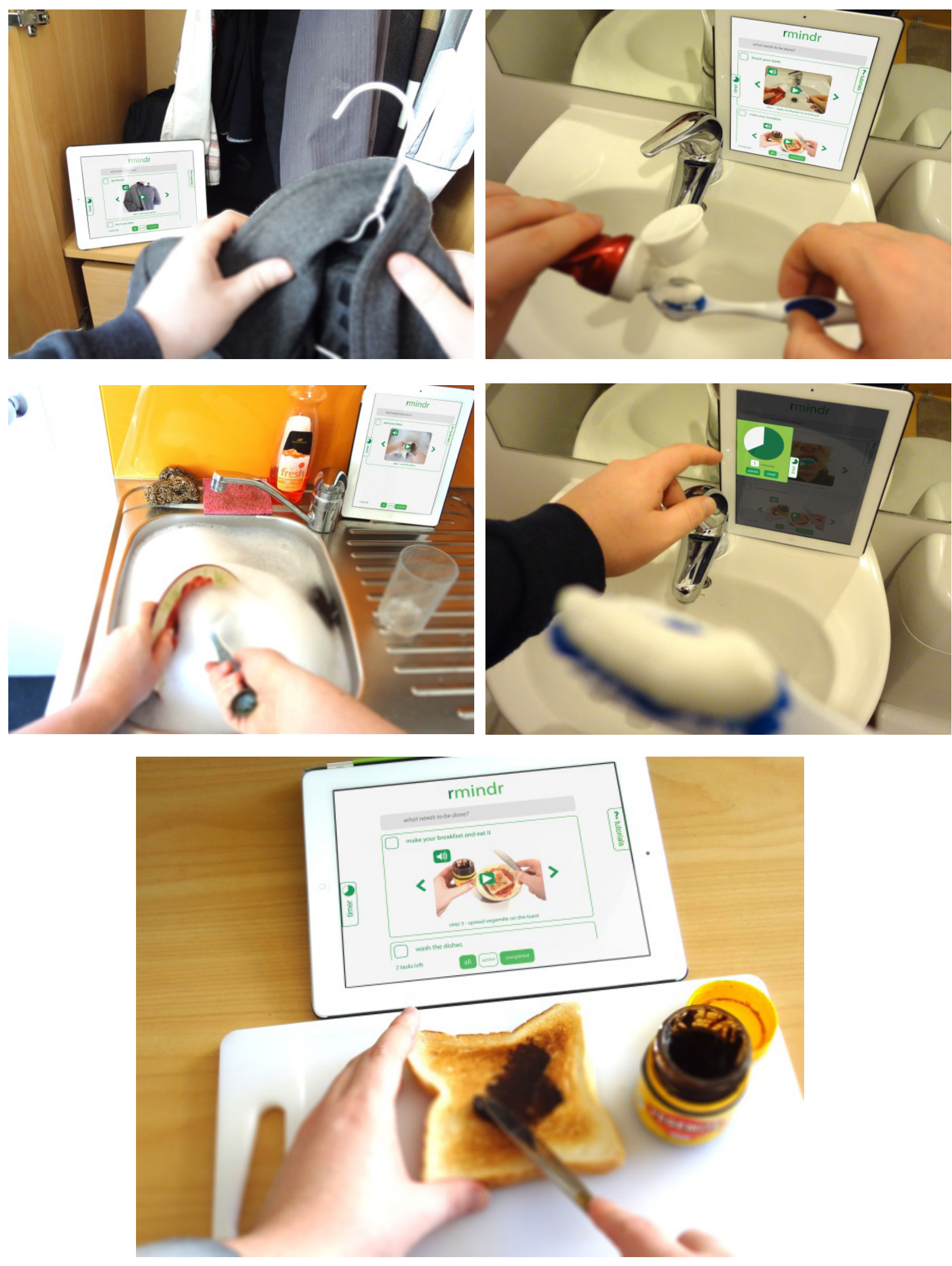
rmindr
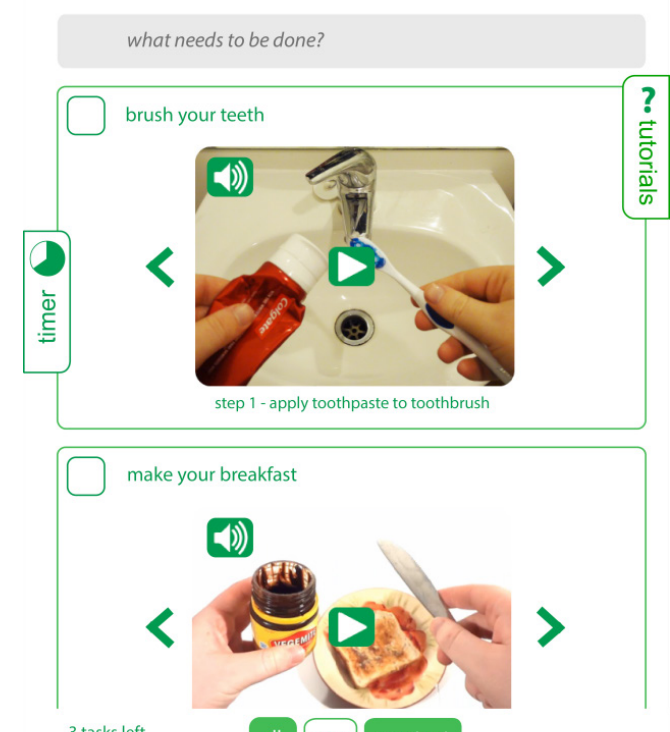

3 tasks left

all active completed
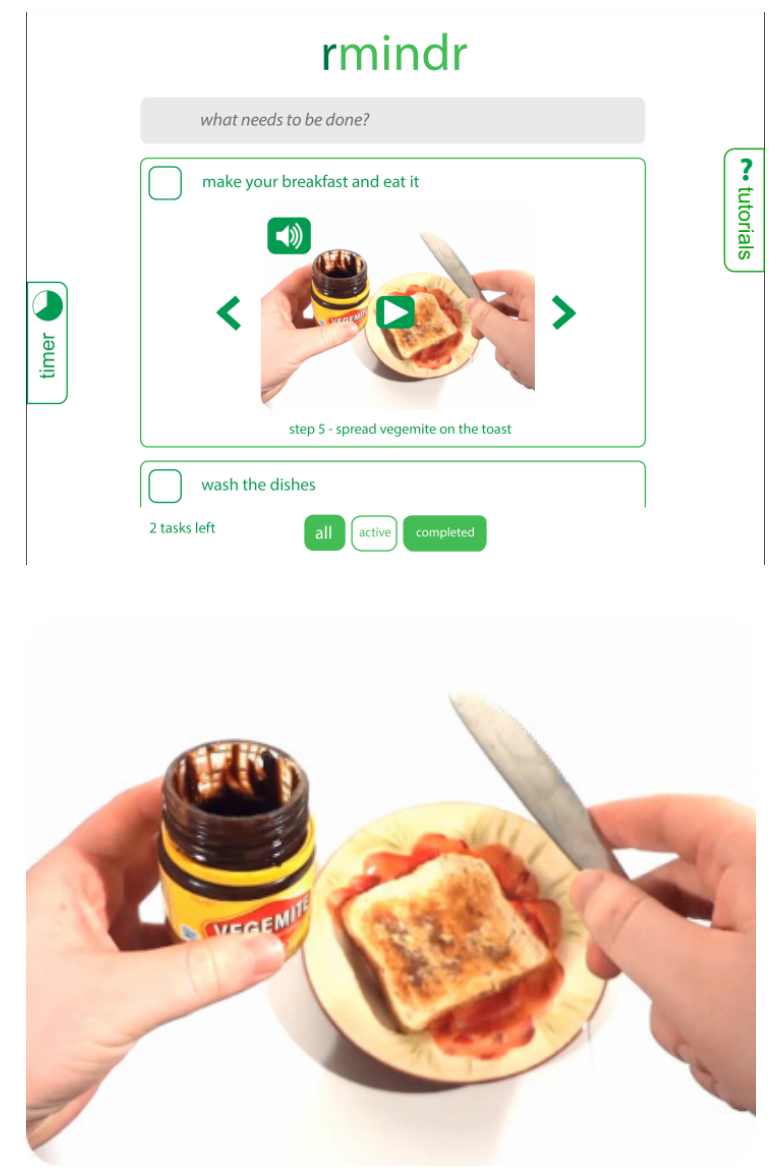

\section{rmindr}
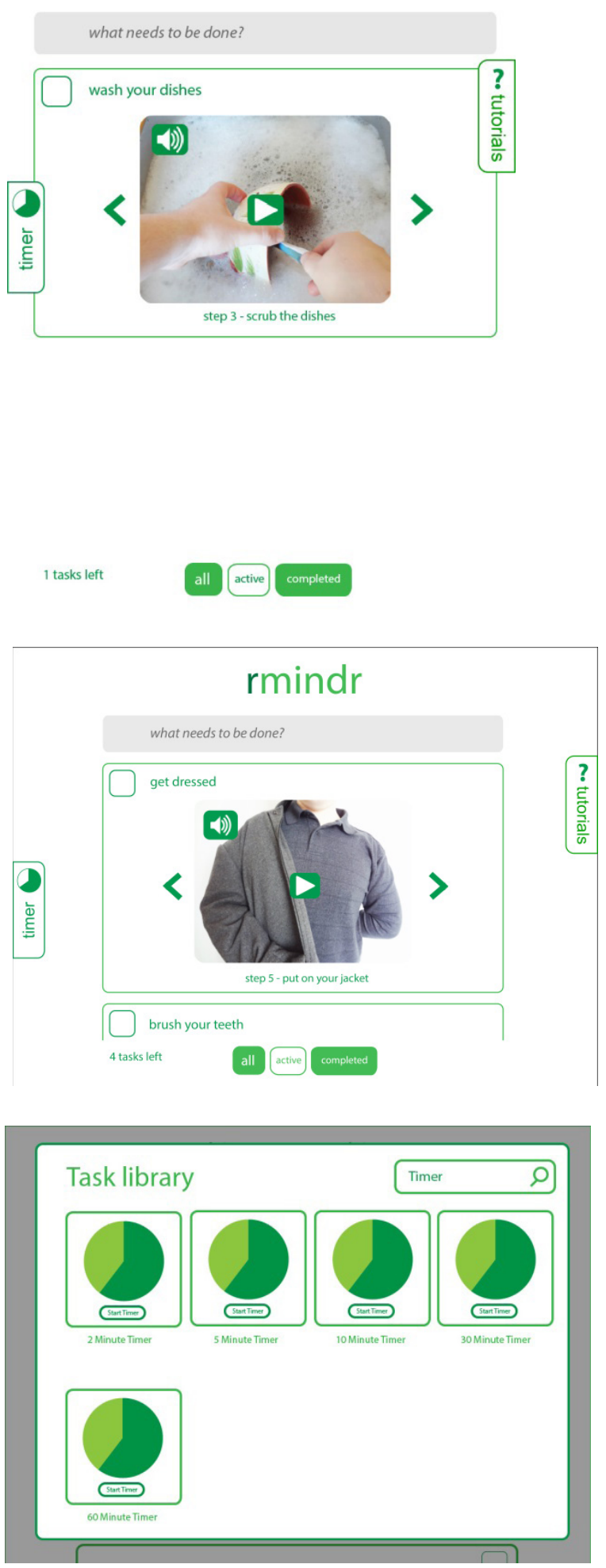

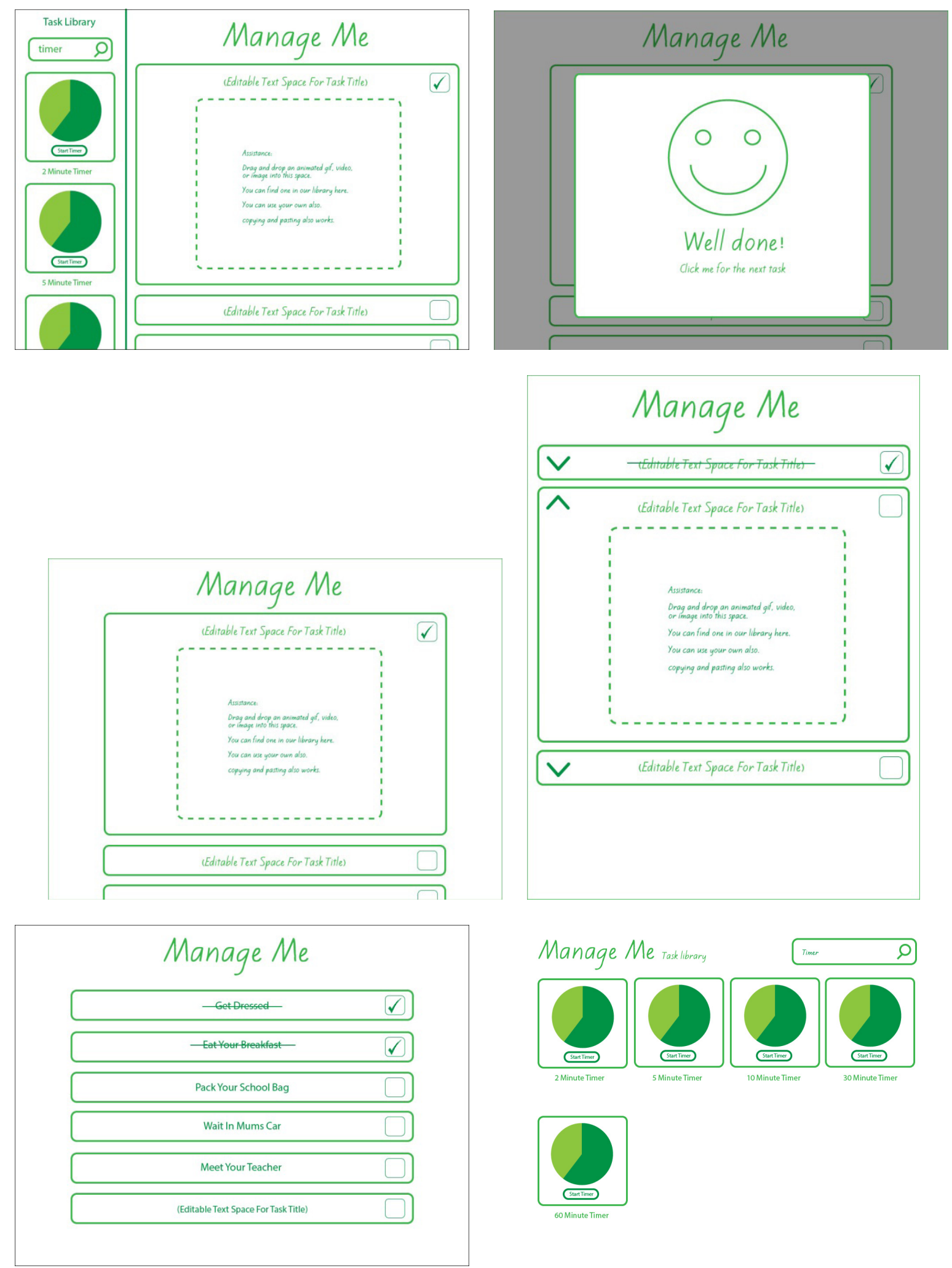

Manage Me taskibrary
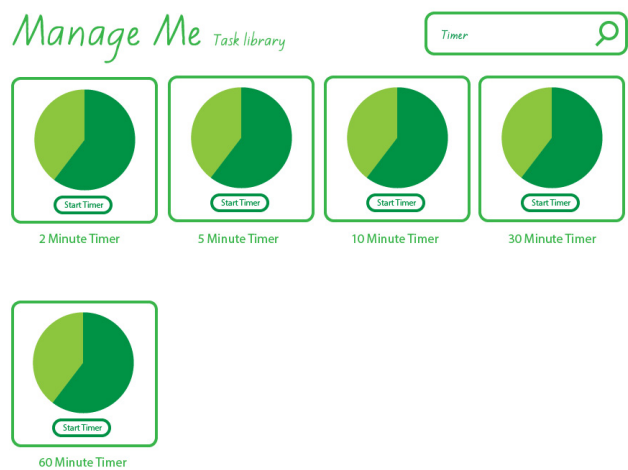


\section{Ethics Approval Form}

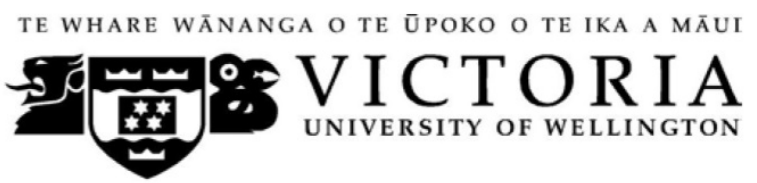

MEMORANDUM

Phone 0-4-463 5676

Fax 0-4-4635209

Email_Allison.kirkman@vuw.ac.nz

\begin{tabular}{l|l}
\hline TO & Broughton Elliott \\
\hline COPY TO & Kah Chan \\
\hline FROM & Dr Allison Kirkman, Convener, Human Ethics Committee \\
\hline DATE & 20 September 2013 \\
\hline PAGES & 1 \\
\hline & \\
\hline SUBJECT & $\begin{array}{l}\text { Ethics Approval: 20224 } \\
\text { Autism, Visual Thinking, and Independence }\end{array}$ \\
\hline
\end{tabular}

Thank you for your application for ethical approval, which has now been considered by the Standing Committee of the Human Ethics Committee.

Your application has been approved from the above date and this approval continues until 4 December 2013. If your data collection is not completed by this date you should apply to the Human Ethics Committee for an extension to this approval.

Best wishes with the research.

Allison Kirkman

Human Ethics Committee

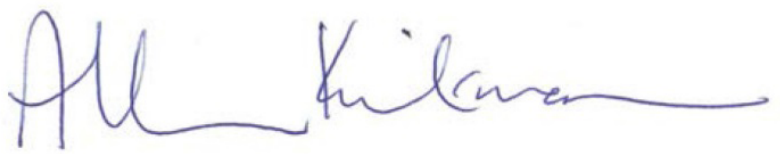

